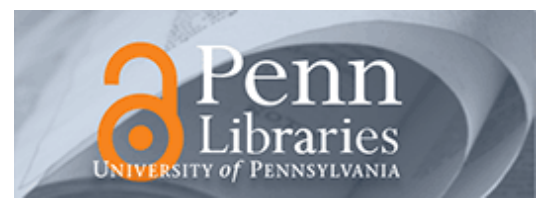

Studies in Visual Communication

Volume 9

Issue 2 Spring 1983

Article 2

1983

\title{
Seen to Be Believed: Some Problems in the Representation of Gay People as Typical
}

Richard Dyer

\section{Recommended Citation}

Dyer, R. (1983). Seen to Be Believed: Some Problems in the Representation of Gay People as Typical. 9 (2), 2-19. Retrieved from https://repository.upenn.edu/svc/vol9/iss2/2

This paper is posted at ScholarlyCommons. https://repository.upenn.edu/svc/vol9/iss2/2

For more information, please contact repository@pobox.upenn.edu. 
Seen to Be Believed: Some Problems in the Representation of Gay People as

Typical 


\section{Seen to Be Believed: Some Problems in the Representation of Gay People as Typical}

\section{Richard Dyer}

\section{The Importance of Gay Typification}

A major fact about being gay is that it doesn't show There is nothing about gay people's physiognomy that declares them gay, no equivalents to the biological markers of sex and race. There are signs of gayness, a repertoire of gestures, expressions, stances, clothing, and even environments (see Figure 1) that bespeak gayness, but these are cultural forms designed to show what the person's person alone does not show: that he or she is gay. Such a repertoire of signs, making visible the invisible, is the basis of any representation of gay people involving visual recognition, the requirement of recognizability in turn entailing that of typicality. Though not indispensable, typification is a near necessity for the representation of gayness, the product of social, political, practical, and textual determinations

\section{Social}

All societies categorize objects, animals, persons, and behaviors, and it is hard to imagine how it could be otherwise. This is the means by which societies order the world and make sense of it. Such categories require words and images to represent them. "Homosexual" and "lesbian" are only two of the many categories, words, and images of sexuality that contemporary Western societies designate or recognize.

That much we can, hopefully, agree on. Recent thinking, however, has been concerned to show that while categorization may be a general activity of human societies, the categorization of sexuality is not. It is argued that not only such sexual categories as lesbian and homosexual but also the activity of sexual categorization itself are historically specific, and indeed relatively recent, phenomena. In this view, sexuality is seen to have been granted a privileged position in the explanation of human affairs; sexual behaviors have been assumed to belong to types of persons who perform them, words like "homosexual" and "lesbian" thus designating persons not acts; and a taxonomy of such sexual types has been produced, not only in psychosexual therapy but also in popular culture and common sense.

Richard Dyer teaches in the Department of Film Studies at the University of Warwick, England, and has written widely on film and other aspects of contemporary culture.

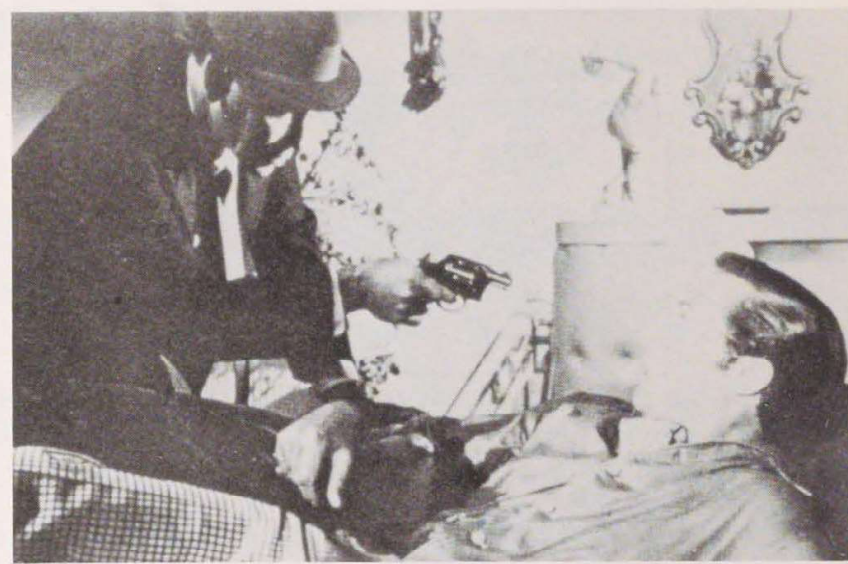

Figure 1 The Detective, U.S.A., 1968. Production still.

There are a number of problems with this view of the emergence of the homosexual category. It is lacking in sustained empirical evidence and often extrapolates too widely from official or high-culture ideas about sexuality. It is often used in concert with an essentialist view of human sexuality as being "really" either bisexual or polymorphous perverse. It assumes that because there were no terms or images of homosexual persons in a given historical period, there were not persons whose sexual activity was predominantly or exclusively with members of the same sex. In these and other ways this view of the development of sexual categorization needs further thought and research. Yet it does draw attention to salient features of the way our society characteristically thinks about sexuality, namely, the importance accorded sexuality in the understanding of human behavior in general and the conflation of sexual behavior and psychological disposition, the idea of sexual personality types.

\section{Political}

Homosexual and lesbian have been negative sexual categories, at best to be viewed pathologically, at worst as moral degeneracy, and in either case calling forth images in which such features as skin pallor, hooded eyes, and genital deformity have been used as visual correlatives of sickness and sin. Such views of lesbianism and homosexuality have been challenged, above all by those people who found themselves designated by the categories. There have been two predominant forms of challenge. 
One has attempted to alter the object of the categories, to change the terms of what they refer to by shifting from persons to acts. The most familiar form that this argument takes is that people who perform homosexual acts are in every other respect just like everyone else: their sexuality does not imply anything else about their personality. This has been a major plank in the arguments of homosexual civil rights and law reform movements, and it is in the logic of this position that all typification is anathema. The problem was and is that the arguments about homosexuality are very hard to make on the terrain of existing definitions which do inexorably imply categories and types. Thus a statement like "homosexuals are just like anyone else" already reproduces the notion that there are persons designated homosexuals. Moreover, the development of gay subcultures meant that many homosexual people did participate in a life-style, a set of tastes, a language, and so on that meant that their lives were, in more respects than the sexual, different from that of most heterosexual people.

This subcultural activity was itself a form of resistance to the negative implications of the lesbian/homosexual categories, in that it took the categories as a basis for a way of life rather than as something to be overcome or cured. From this subculture emerged the politics of the late-sixties gay movement, with its stress on accepting oneself as lesbian/homosexual, identifying oneself with other homosexual people under the term "gay" and coming out, openly declaring and showing oneself as gay to society as a whole. These strategies of identifying and coming out immediately raise the problem of visibility, of being seen to be gay. Wearing badges, kissing in the streets were means of being visible, but so equally were behaving and dressing in recognizably gay ways - they brought you together in an act of sharing and they made you obvious on the streets. Typification, visually recognizable images and self-presentations, is not just something wished on gay people but produced by them, both in the prepolitical gay subcultures and in the radical gay movement since 1968.

\section{Practical}

Socially, then, in the fact of the sexual categories of homosexual and lesbian, and politically, in the desire for subcultural identification and for coming out on the basis of those categories, homosexual typification is all but inevitable. It also comes to have a practical advantage. Visibility, and hence typicality, means that it is easier for gay people to meet others like themselves. This is most notable in the elaboration of cruising as a major pattern of male homosexual contact. Initially, mere visual obviousness makes it easier for gay men to establish who is gay and who is not; subsequently, different sexual interests can be signalled through a set of dress and other signs, developed enough to be explored semiotically as $\mathrm{Hal}$ Fischer has in his Gay Semiotics (Fischer 1978). In some measure the male gay cruising system would seem to have beaten what Michel Foucault refers to as the regime of the sexual at its own game of delineating with ever-greater specialization a taxonomy of desire.

\section{Textual}

Finally, typification has certain advantages in the production of cultural texts representing homosexuality and lesbianism. First, typification is, as a mode of representation, immediate and economical. It dispenses with the need to establish a character's sexuality through dialogue and narrative by establishing it literally at first glance. Dialogue and narrative may themselves be stereotypical. There are conventional ways of indicating in dialogue that a character is gay-certain topics of conversation often function as the trigger for the discussion of whether another character is gay. For example, childlessness, loneliness, a man's interest in arts or domestic crafts, a woman's in mechanics or sports may be used, each implying a scenario of gay life. As secondary characters, gays have familiar narrative functions - the gay male best friend, the threatening lesbian. When central characters, there are formulaic gay plots: the tussle between a lesbian and a heterosexual man for a sexually unformed woman, a plot often ending in violence, murder, or suicide; the gay male affair that has built into its presentation from the beginning intimations of its inevitably fleeting, and therefore melancholy, quality. Many of these dialogue and narrative conventions may also be immediately presented through visual types, but that is not necessary and is often avoided since much of the dramatic quality resides in the revelation or discovery that a character is gay, or in the teasing doubts and hints that the text offers on the subject. But, equally, this then becomes the subject matter of the text, whereas a quick visual type allows the text to concern itself straightforwardly with homosexuality, not within the formulas of revelation and discovery. 
Second, types use a few easily recognizable signs to convey not just that a character is lesbian or homo sexual but what that implies in terms of a psychology, a social role, and/or a subculture. In a shot from near the end of La dolce vita (Figure 2), we not only at once and without difficulty identify the men second and fourth from the right as homosexual by their dress and hairstyle, but in so doing are also recognizing a great deal else. We are drawing on our knowledge of the very notion of homosexuality and hence of heterosexuality and the whole conceptual system of sexualities that they fit into. We are also drawing on a knowledge of the social forms this takes, of the subcultural styles of gay men. This is not just taxonomic knowledge, an ability to slot someone into the correct social category, but value-laden. We recognize these men as gay not just because those are the kinds of clothes and haircuts gay men wear, but because that sort of appearance is related to certain assumptions about gay men, especially their relation to gender. That sort of appearance has qualities - the tactility of the sweater, the pretty patterning of the scarf, the carefully adjusted set of the collar, the crimped, set look of the taller man's hair - that are associated with femininity in our culture. We know these men are gay because we see aspects of them as in some sense feminine. This implies a conflation of sexuality and gender roles that is characteristic of gay types; I shall return to this point below. What I want to stress here is the way in which such small details of an image can so quickly and assuredly summon up such a breadth of social implication, can condense such a wealth of meaning and knowledge (see Perkins 1979).

Finally, types keep the fact of a character's gayness clearly present before us throughout the text. This has the disadvantage that it tends to reduce everything about that character to his/her sexuality. It has the advantage that it never allows the text to closet her or him, and it thus allows gay subcultural perspectives to be always present in a scene. For gay readers and audiences, in particular, this allows a place in the text from which to view the proceedings.

The prevalent fact of gay typification is determined by the importance of a social category whose members would be invisible did they and the culture not provide life-style signs with which to make recognition possible. It should be added that it is probable that most gay people are for most of their lives in fact invisible. Acting and dressing gay may be only an evening or weekend activity; in particular, it may not be practiced at the workplace, or for married gays at home either. Equally, many people who are homosexual may never identify with the various gay life-styles, never, in this sense, define and produce themselves as gay.

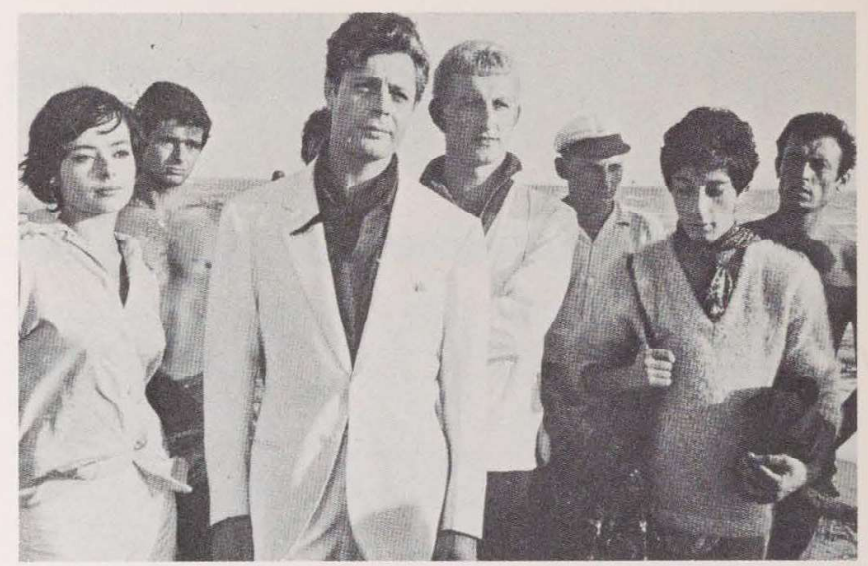

Figure 2 La dolce vita, Italy, 1960. Production still.

\section{Sexuality/Gender/Biology/Nature}

The majority of gay types signify gay sexuality through signs that also have gender connotations. Gay types are thus bound up in this double way with notions of the natural, whether these be cast more within biological discourses or more within romantic traditions of perceiving nature

That this should be so is hardly surprising since our notions of both sexuality itself and sexual variations are themselves biological. I mean this in the loosest sense, that ideas about human sexuality have been insistently organized in terms of what is given by nature, by what John Gagnon and John Simon refer to as the notion of a "basic biological mandate" (Gagnon and Simon 1973), whether that be the urge to reproduce or the need for orgasm or the drive for sexual release. A major aspect of this biological view of sexuality has been the attempt to determine and differentiate male and female sexualities, so that not only are sex and gender conflated (biological sex being deemed to produce psychological gender dispositions), but so are sex and sexuality, there being a sexuality appropriate to the two biologically distinct sexes. Although these sexualities have been predominantly defined in terms of heterosexuality, they have perhaps more importantly been defined in terms of male and female sexual predispositions, of which the active male drive and the passive female receptivity are the most familiar examples. Thus it is not the act of heterosexual intercourse that makes someone heterosexual, but one or another psychosexual predisposition which is heterosexual only in the sense that an active drive and a passive receptivity are seen to be inherently complementary.

For various reasons this kind of thinking, although at the level of common sense undoubtedly still dominant today, has been roundly rejected in many quarters. The case against it can be made on the grounds of the anthropological and historical evidence of the enormous differences in the construction of both gender and sexuality in other cultures and other times, but the force of the rejection is above all political. In part it springs from a rejection of all models that root understanding of human society so firmly in the bio- 
logical. Not only sex and sexuality but also race are all biologically based notions that have historically been used in infamously destructive ways, of which the Nazi designation of biologically inferior peoples (races and sexualities) and medical experimentation on them is only the most obscene. The sexist bias in biological theories of sex and sexuality was very clearly demonstrated by feminist writing in the late sixties and early seventies. More recently, the work of Michel Foucault has been influential in spreading the idea that sexuality, precisely by its intimate and apparently biologically given character, is the aspect of human lives that is most open to the exercise of power relations in modern society, that it is through the regulation of our bodies in the regime of sexuality that we are controlled

In general I would share the emphases of all these arguments, but it is important to recognize that arguments from biology are not necessarily and always reactionary. If a major assumption of many biological arguments is that what can be shown to be natural must be accepted as a proper part of human life, then it is not surprising that those arguing for the rights of gay people have often sought to show that gayness too is natural: hence, on the one hand, the attempt by campaigners like Edward Carpenter and Magnus Hirschfeld to show that gays are a third or intermediate sex (see Figure 3) or, on the other, the importance of the rhetoric of naturalness in much contemporary lesbian art. Though there is a culturally very significant shift here from a more biological to a more romantic-naturalist world view, both are arguing for the rights of gay people from a model of nature. It is their conception of nature that is different, not the form of the argument.

\section{Another Argument, Another Type: The Classical Model}

Other kinds of argument are possible, hence other sets of types, although those based on biology/nature have proved most successful in our time. One alternative argument has been drawn from classical example. If in relation to female homosexuality this has largely been confined, as far as I can see, potently to the use of the words "lesbian" and "sapphic," in relation to male homosexuality it has produced, in addition to the rhetoric of which Wilde's "love that dare not speak its name" speech is the most celebrated example, a particular range of visual images.

The classical example could be for men a way of representing desire, both in the sense of imaging it to themselves and in the sense of arguing for it to the world; it could be both the form of desire and the defense of it. This inspiration from classical antiquity, which is of course based on the nineteenth-century

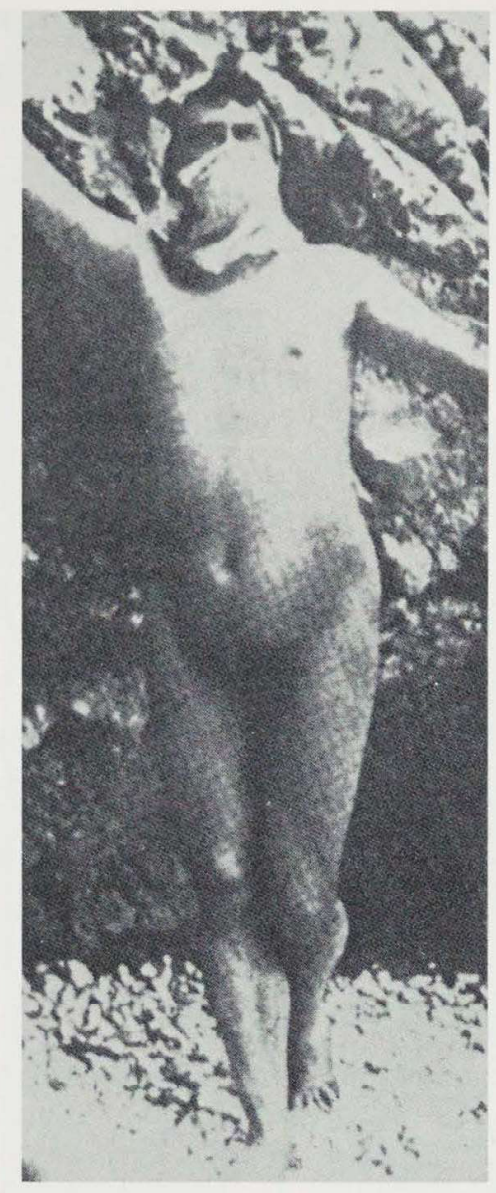

Figure 3 "Intermediate type," published by Magnus Hirschfeld in volume 1 of the 1903 Jahrbuch für sexuelle Zwischenstufen (Yearbook for Intersexual Variants). understanding of the classical, is classical in two senses. First, it invokes the period of classical antiquity as an unquestionable touchstone of the finest achievements of the human race-if gayness can be shown to be characteristic of the classical age, then how can it be condemned now? Second, the argument is itself classical rather than romantic or biological insofar as it is based on the notion of the ideal example to be followed, rather than on what is given in nature. It has thus the character of a moral argument rather than a rational or pragmatic one. The types that derive from it are not only available for both formal and defensive representation but bathe both in a morally idealistic glow.

The costume balls of Stefan George, whose fame as a poet ensured that they became widely known (if as much through ridicule as emulation), were in their adoption of Greek and Roman garb and props (see Figure 4) both rituals of desire-as balls generally are-and the enactment of a homosexual ideal that had something of the force of propaganda. Some of the earliest gay rights publications, such as Der Eigene (first published in 1896), used classical motifs so that they both argued for gayness and provided their readers with attractive embodiments of gay desire (see Figure 5); but also soft male gay pornography has often used classical reference, both in the poses of the models and in the use of vaguely classical props (see Figures 6 and 7). Among the most cel- 


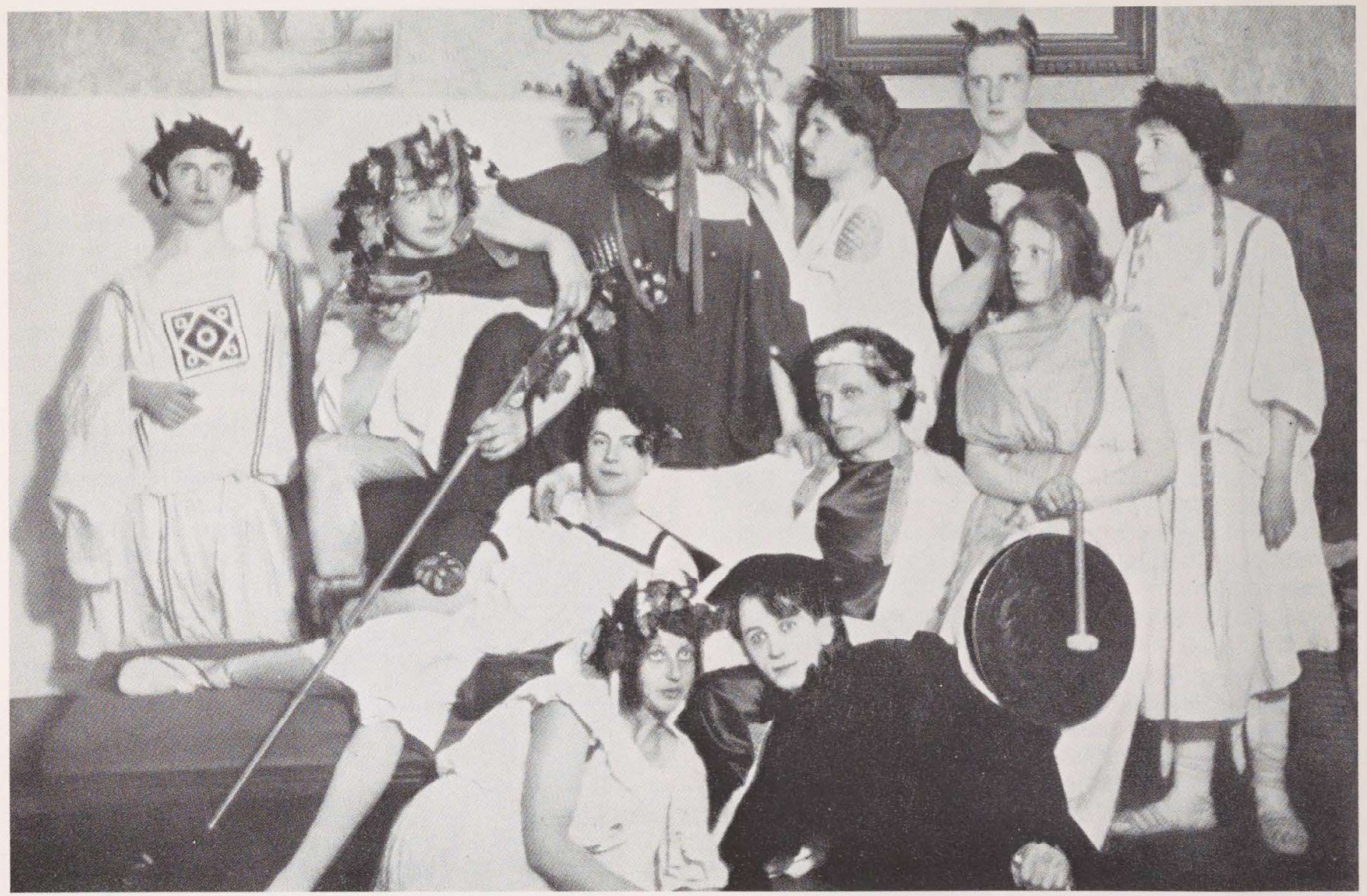

Figure 4 Costume ball at Stefan George's house, n.d. From Robert

Boehringer, Mein Bild von

Stefan George,

Düsseldorf, 1967, p. 89.

ebrated images of this kind are the photographs of Wilhelm von Gloeden, which not only use classical poses and props and quite literally bathe the subjects in a pure "classical" light but also concentrate on the adolescent male, the ephebe supposedly so central to the classical construction of homosexuality.

Despite the coherence and appeal of this tradition, however, it has largely been superseded in gay cultural production and has never been widespread in dominant representation of homosexuality. This is due in part perhaps to its proselytizing dimension, but more centrally to the fact that arguments from (moral and aesthetic) ideals have little force in our culture compared to arguments from biology/nature. It is these that predominate in both mainstream and gay subcultural homosexual types.

\section{Four Types}

I want to describe here four predominant gay types. Obviously these do not exhaust the range of gay types in the culture. They illustrate two themes already discussed: the importance of gender and of biology/nature in gay representation, and the pressure from both dominant and subcultural forces to produce gay types. One aspect of the latter that emerges is the way in which the same types may have different meanings and functions in mainstream and subcultural contexts. Two further points may be noted. As mentioned in discussing the use of the argument from classical example, gay types may be both the form of desire and a defense of it; further, they may embody both what it is like to be gay and what it is gay people find attractive-gay types can embody both the subject and the object of desire. Finally, it is clear that any gay type will inflect and articulate other traditions of representation in the culture as a whole. Ideas of sexuality and gender, biological 


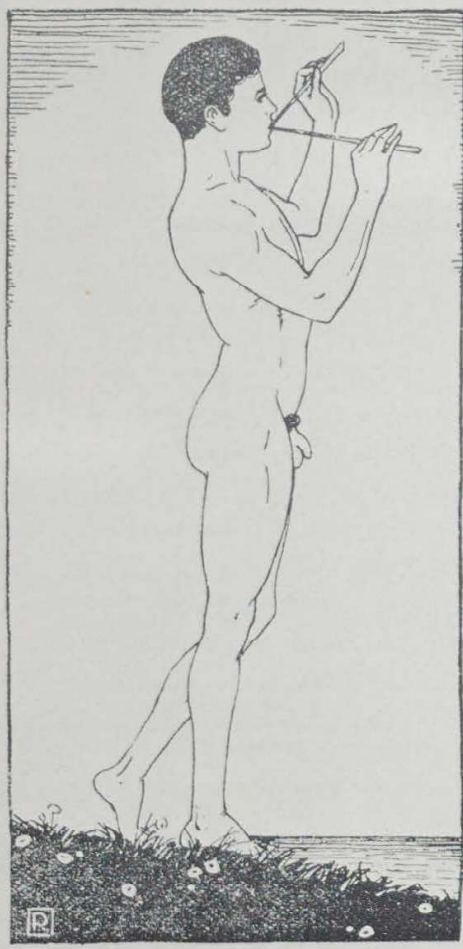

FLÖTENSPIELER

ZEICHNUNG VON KARL POTHS

Figure 5 "Fluteplayer."

From Der Eigene, n.d.

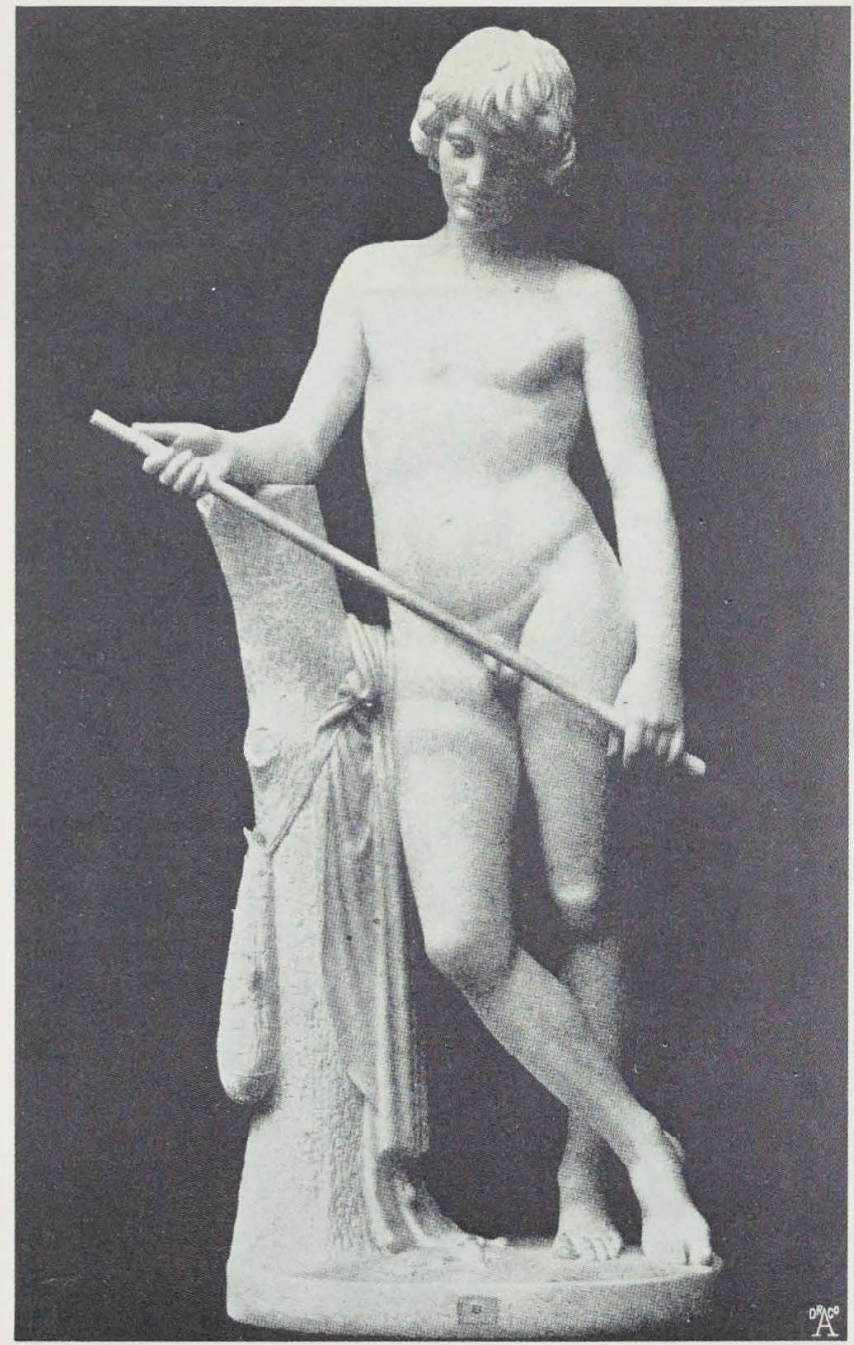

Figure 6 "Fisherboy."

From Der Eigene, 1903. and romantic conceptions of nature are such traditions, as are, for example, bodies of religious and secular myth. Gay types are always caught up in the total web of the system of cultural meanings; what they mean has in part to be understood through this web of meanings.

Most of my examples are drawn from films, though I shall make reference to other media. This is partly because films are my particular area of competence, but the cinema has probably been more significant as a central definer of sexualities than any other cultural institution in our century, including television, where the representation of sexuality has been severely restricted. Many of the examples discussed are production stills, not frame enlargements; they are photographs taken on set during production, deliberately posed for the still photographer and intended for use in publicizing and marketing the film. They are interesting because they are produced and selected for use with the aim of suggesting or even summing up the entire film or an aspect of the film. In this sense they are even more liable to lean heavily on typifica- tion in order to convey an idea of homosexuality than the film itself may have been. Equally, in their wide availability and reproduction, they may fix the gay type more definitively for the viewer than the memory of the film itself does. 


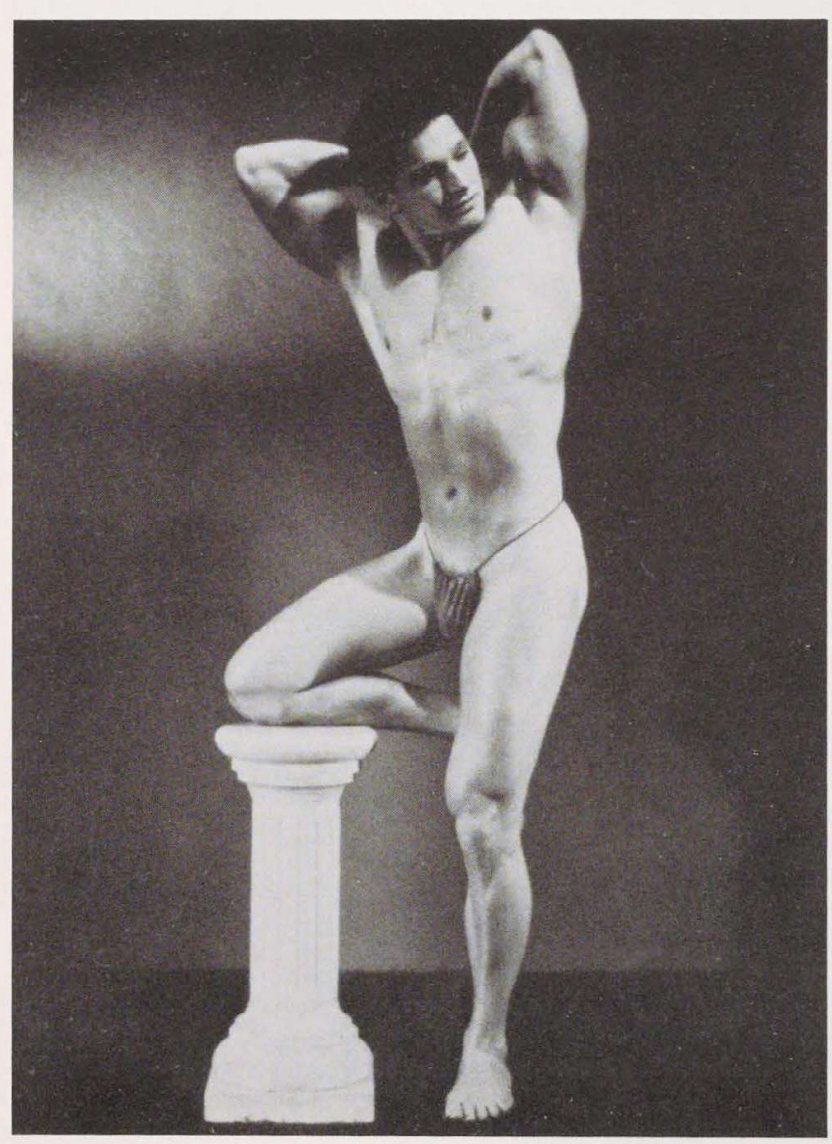

Figure 7 1950s "physique" photo.

\section{In-betweenism}

Probably the most familiar gay types are the queen and the dyke. Although I shall designate them thus singly, there are any number of variations on each. This production still from The Killing of Sister George (Figure 8) shows, as the film does, two versions of the dyke type - both with cropped hair and wearing mannish clothes, but George/June at the back is in tweeds, has a more fully masculine cut to her suit, and uses no makeup, whereas Mercy Crofts in the center wears a bright red (primary not pastel colors being more "masculine") dress with a more "feminine" rounded collar and makeup which is, however, applied with expert, military precision, giving her face a hard-edged look. Both are dyke types, though Mercy is the more ambivalent as befits her role in the film. Both types connote different notions of masculinity: tweed suggests traditional, rural, rough masculinity, whereas Mercy Crofts's appearance suggests the modern, professional, business milieu. Both, however, also connote the upper middle class. Elsewhere in the film, in the sequence at the Gateways Club, other more working-class dyke types are present. Similarly, there are many variations on the queen type, and these often inflect other values - whether, for instance, of aesthetic sensibility, as in the contrast between a queen working in the trivial art of fashion (see Figure 9) and the exquisite aestheticism of Sebastian in Suddenly Last Summer (Figure 10), or else of ethnic difference, as in the contrast between the two examples just mentioned and Lindy in Car Wash (Figure 11). I do not intend, however, to offer an exhaustive taxonomy of the inflections of the dyke and queen types; my purpose here is simply to indicate that each is a type found in many well-established variations which cross with other social and cultural types and value systems.

The queen and the dyke both represent homosexuality through what is assumed to be a gender correlation - that is, both are represented as if their sexuality means that they are in between the two genders of female and male. Thus dykes are mannish, queens effeminate. The examples already cited, from La dolce vita and The Killing of Sister George, illustrate this directly.

We are familiar with the use of these types as putdowns. The form this often takes is the tag that gay men and lesbians are not "real men" and "real women," which expresses the assumption that true masculinity and femininity are in large measure defined in heterosexual sexuality. However, this negative use of the types should not blind us to the fact that ideas of in-betweenism have been used by gay people themselves, not only in subcultural practices but in historically progressive activism. The arguments of Magnus Hirschfeld were very directly based on ideas 


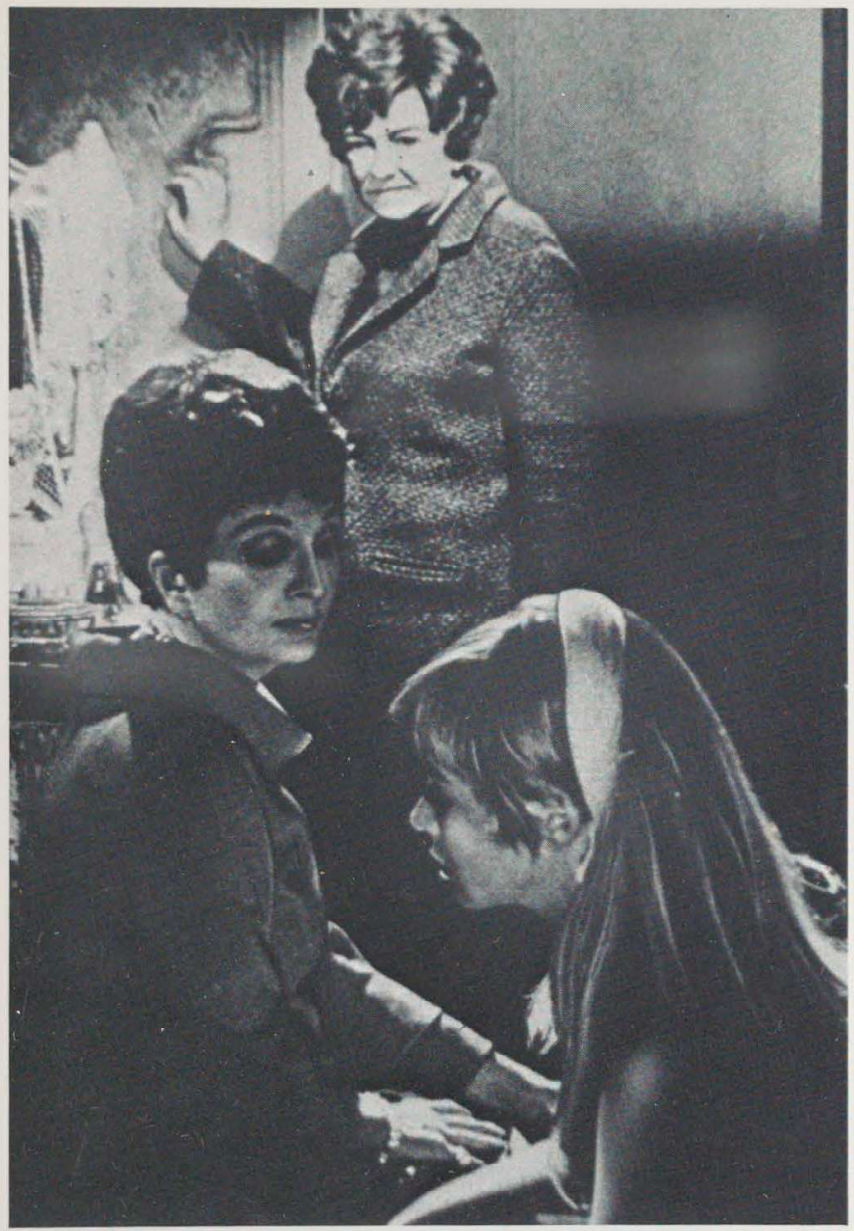

Figure 10 Suddenly Last

Summer, U.S.A., 1957.

Production still. (Courtesy

of Vito Russo.)

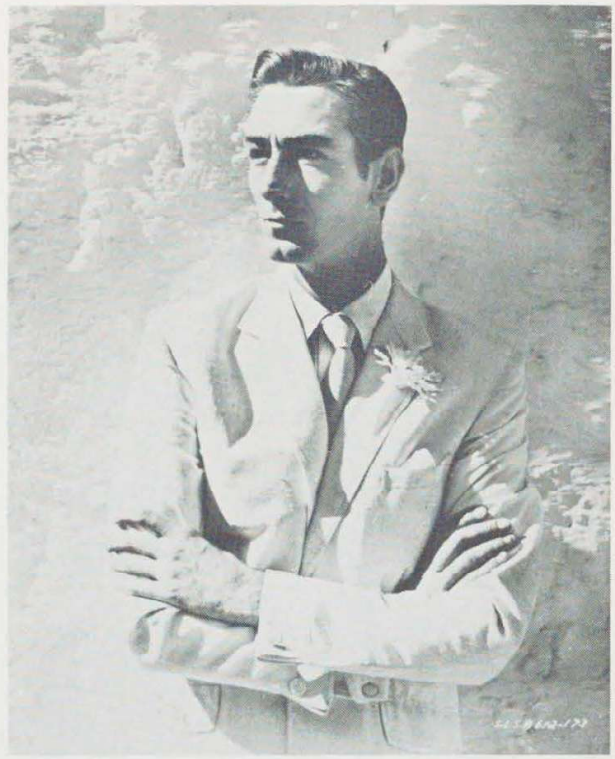

Figure 8 The Killing of

Sister George, Great

Britain, 1969. Production

still.

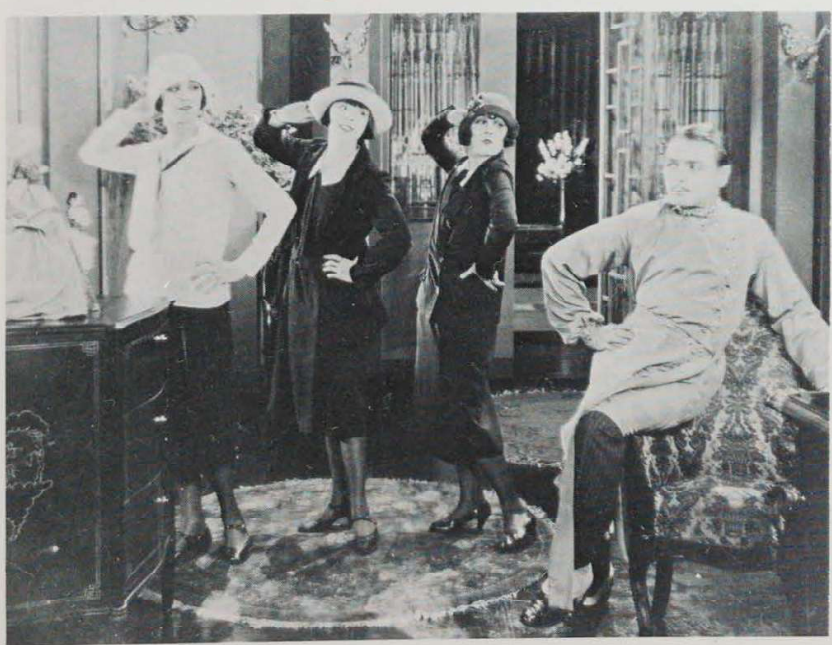

Figure 9 Irene, U.S.A.

1926. Production still.

(Courtesy of Vito Russo.)

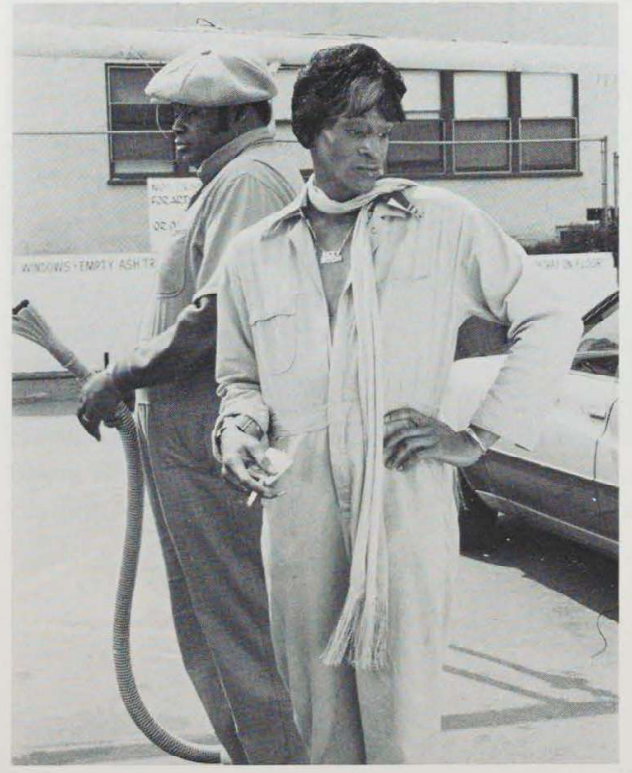

Figure 11 Car Wash,

U.S.A., 1976. Production still. (Courtesy of Vito Russo.) 


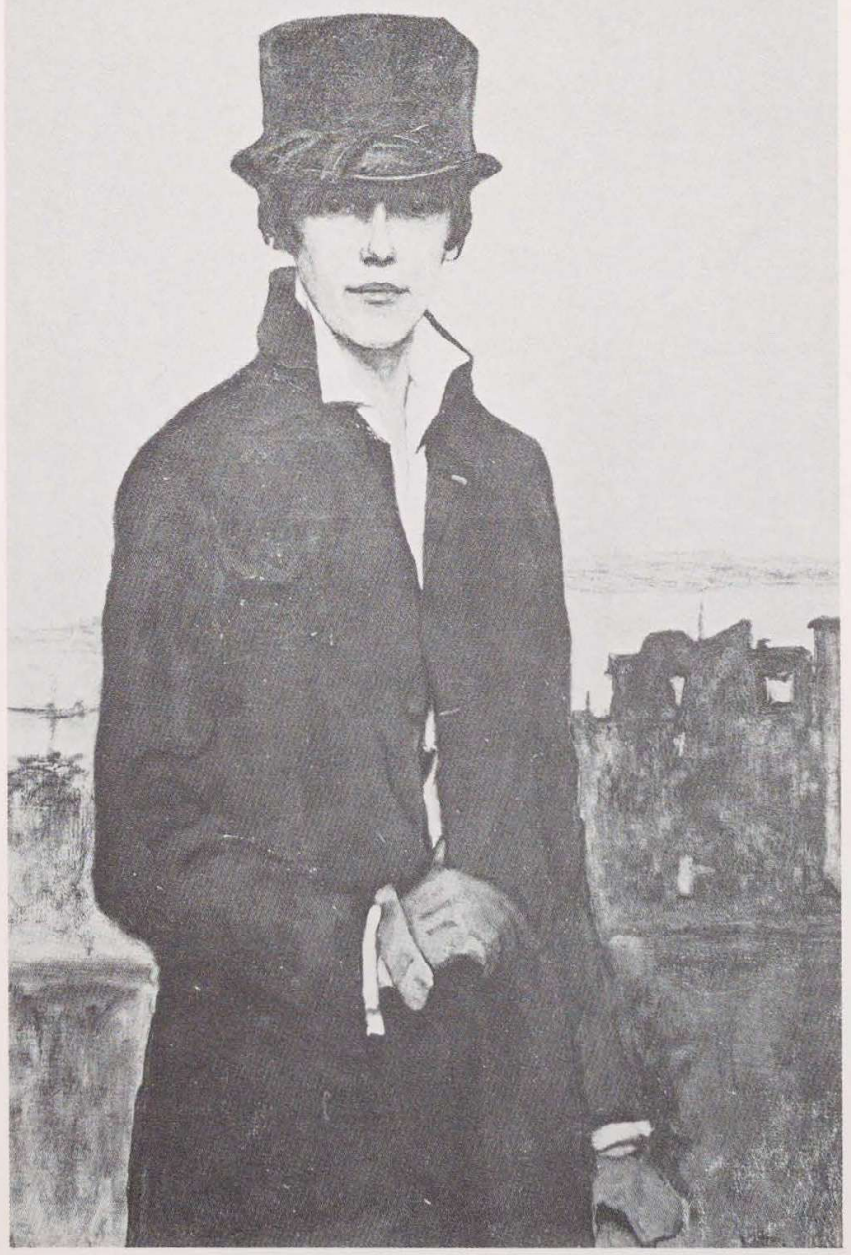

Figure 12 Romaine

Brooks, Self-Portrait,

1923.

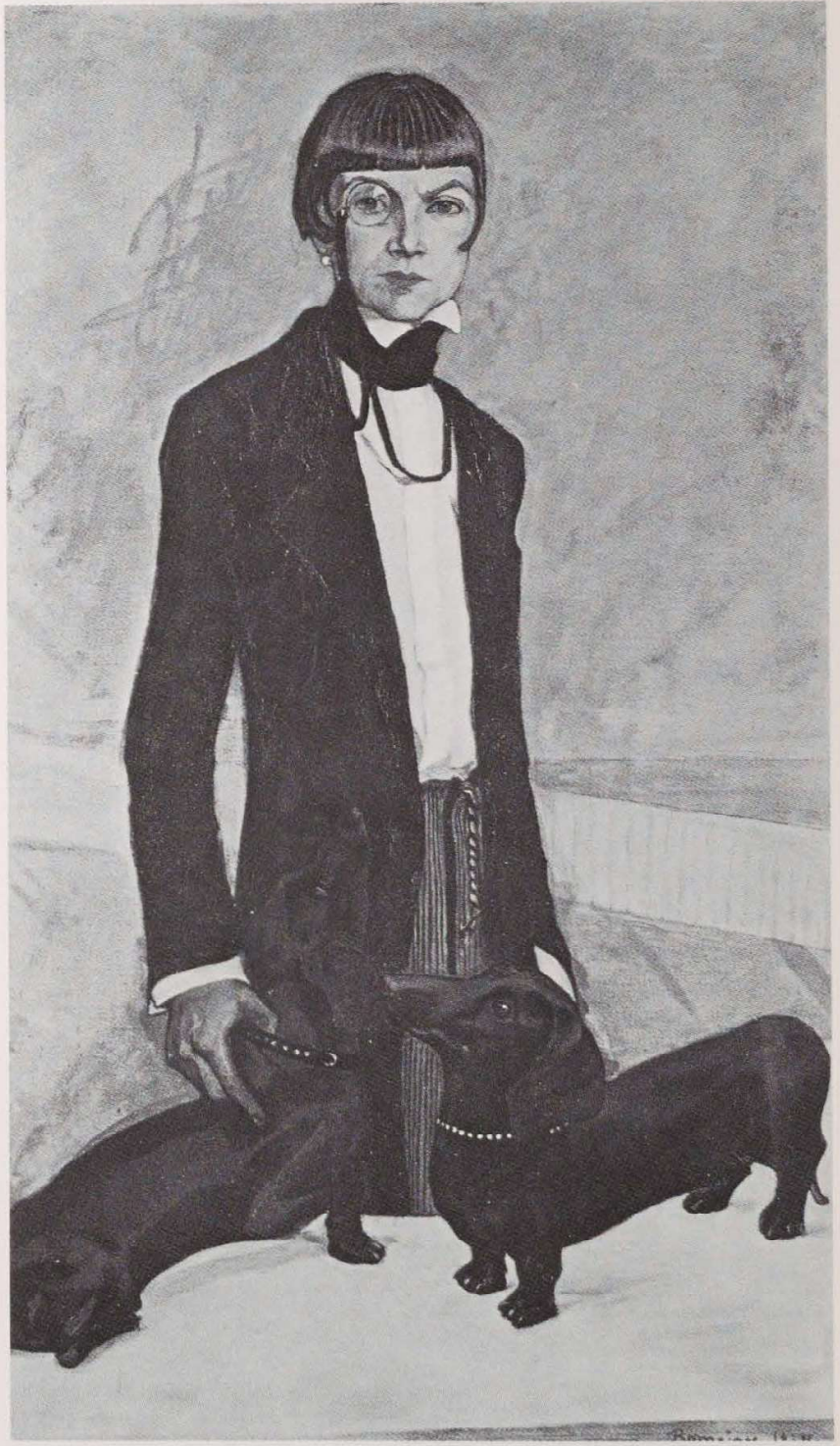

Figure 13 Romaine

Brooks, Una, Lady

Troubridge, n.d. 

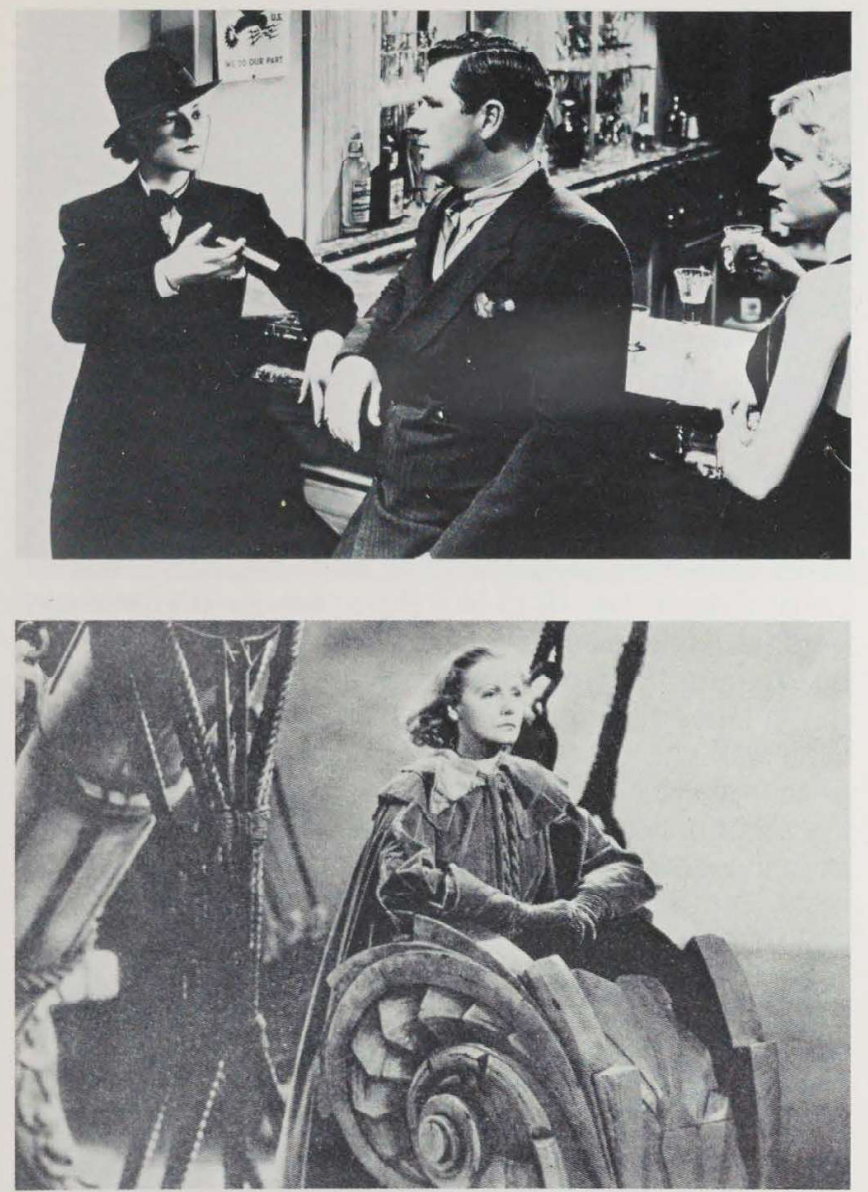

Figure 15 Greta Garbo as

Queen Christina, 1933.

Publicity shot.
Figure 14 Blood Money,

U.S.A., 1933. Production

still. (Courtesy of Vito

Russo.)

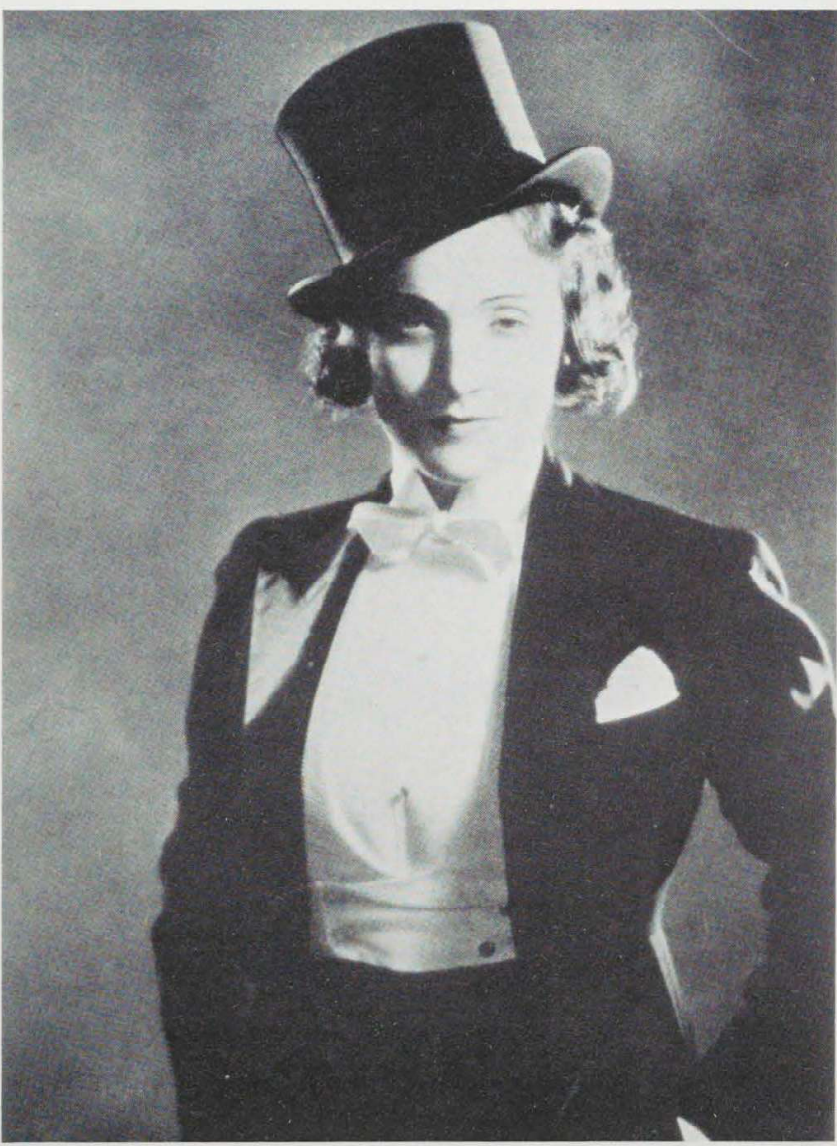

Figure 16 Marlene

Dietrich. Publicity shot. 


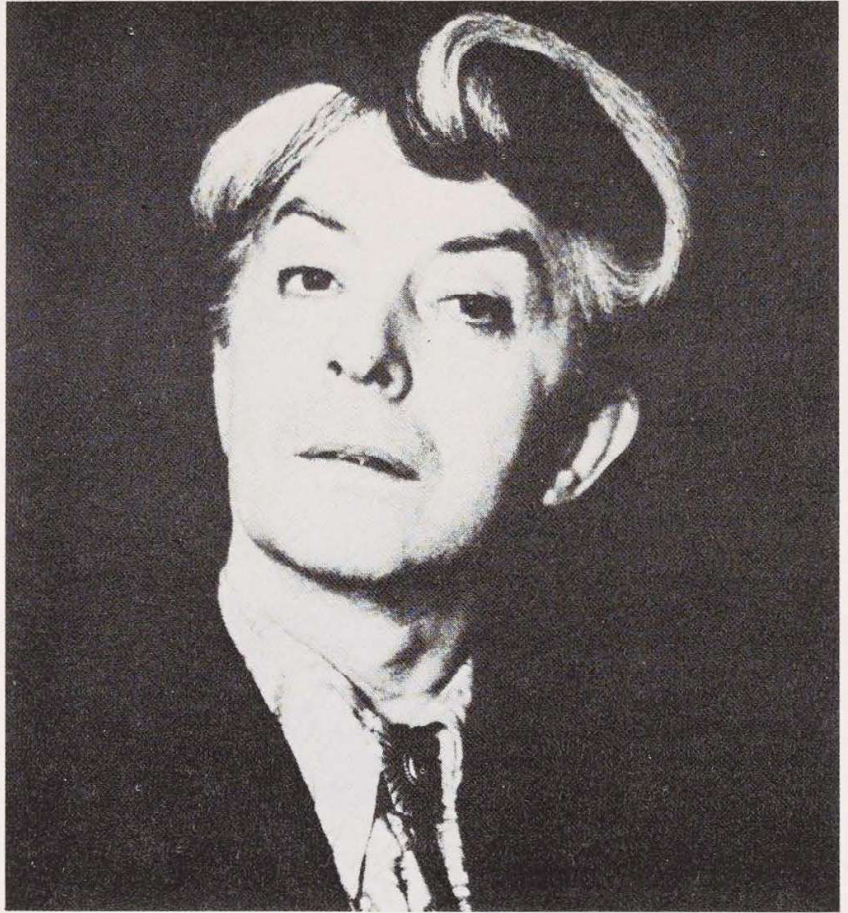

Figure 17 Quentin Crisp. Photograph illustrating interview in British gay magazine, Jeremy, vol. 1 , no. 4, 1969.

Figure 18 The Naked Civil Servant, Great Britain, 1977. (Courtesy of Vito Russo.)

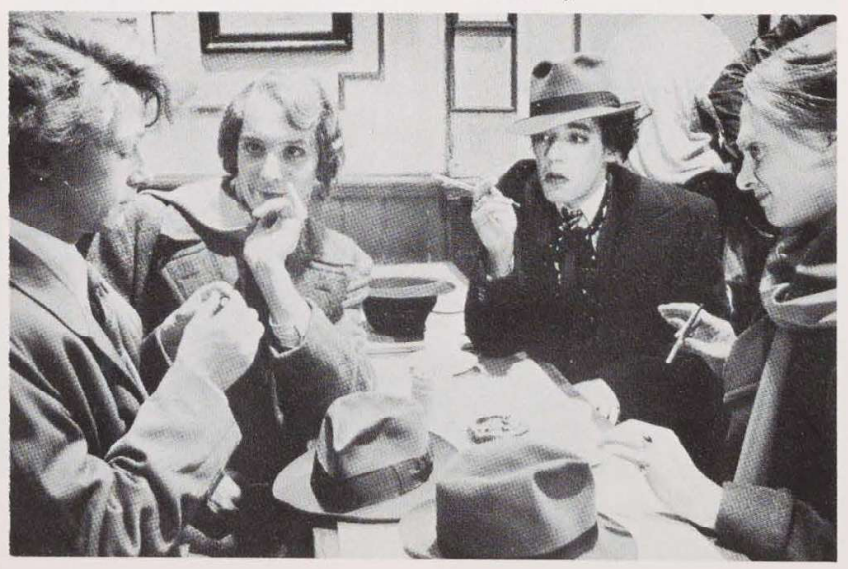

of gay people as a biologically intermediate sex, and he had photos to prove it (see Figure 3). Equally, figures like Radclyffe Hall, Romaine Brooks, and Una, Lady Troubridge, both in their own publicly prominent adoption of a dyke style and in Brooks's reproduction of them in her painting (see Figures 12 and 13), were proclaiming an in-betweenist lesbian life-style in a defiant, declamatory fashion. It is clear where the aristocratic dyke in the 1933 film Blood Money (Figure 14) gets her style from, and equally why a gay following has accrued to stars prepared to appear as Garbo did in Queen Christina (Figure 15) or Dietrich in her films with von Sternberg (Figure 16). This was not only important in its time but has been important in the reclamation of our history, which has stemmed from the development of the post-sixties gay movement. A queen figure like Quentin Crisp becomes crucial here; his life as an "out" effeminate homosexual is seen as exhibiting exemplary courage in his visual display of himself as a queen before coming out became an established strategy of the gay movement. The enshrinement of this in an acclaimed television film put queenliness in the mass public eye, and at the same time he became a focus for debate about the value of the role, its progressive force for us now (see Figures 17 and 18). As I argue in the review essay in this issue, this legacy of the queen (or sissy) type, as of the dyke (or butch lesbian) type, is both challenging and confusing to contemporary gay political thought.

I have referred to the queen and dyke types as effeminate and mannish, and much of the force of the image is that gay men and lesbians are, by virtue of their sexuality, in some sense more like the biologically opposite sex. Yet they are not exactly masculine or feminine either. In gay usage, they may be an assertion of in-betweenism or more generally of a refusal of rigid sex role-playing; but in their use within the dominant culture they are more characteristically portrayed as people who in failing, because of not being heterosexual, to be real women or men, at the same time fail to be truly masculine or feminine in other ways - dykes are unwomanly but fall short of being truly masculine; queens are unmanly and unwomanly. Both are thus often seen as tragic, pathetic, wretched, despicable, comic, or ridiculous figures.

This calls forth the violent and melancholy narratives suggested above, and with it certain predominant inflections of the types. This is particularly elaborated with the dyke, who is frequently represented as dangerous and threatening. It is remarkable how often she is shown positioned in the same ways behind the sexually indeterminate (i.e., she might "go either way") woman (see Figures 19-21). In this pose she appears to be trying to draw the indeterminate woman into her thrall, not by direct assault 


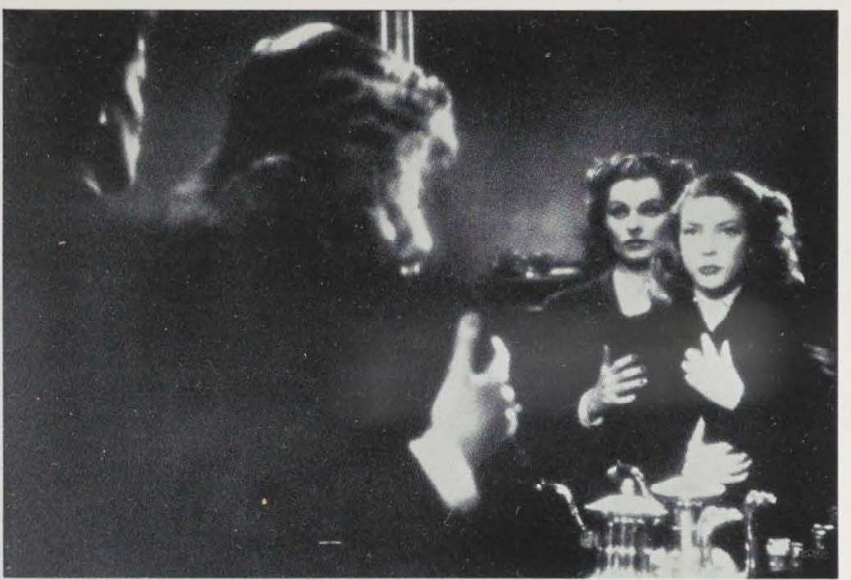

Figure 19 Roma, città

aperta (Open City), Italy,

1945. Frame enlargement.

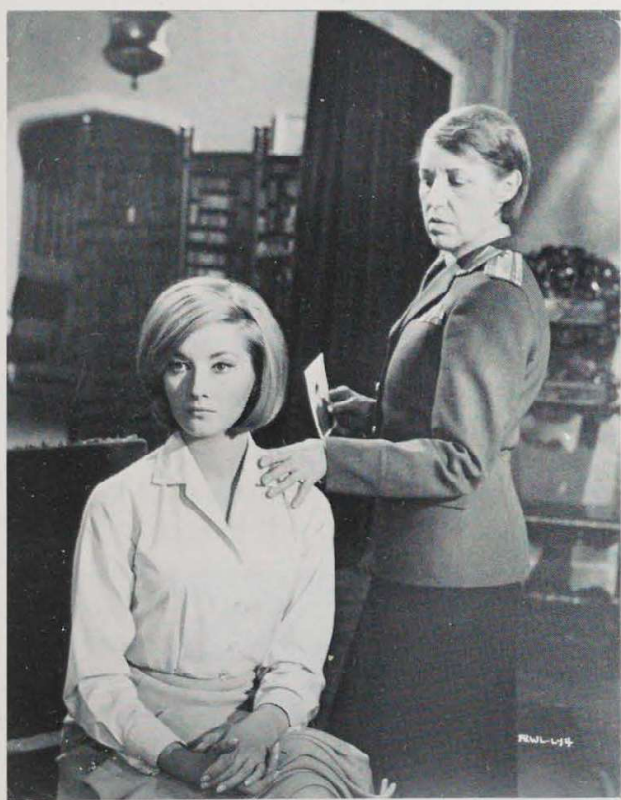

Figure 21 From Russia with Love, Great Britain, 1963. Production still. (Courtesy of Vito Russo.)

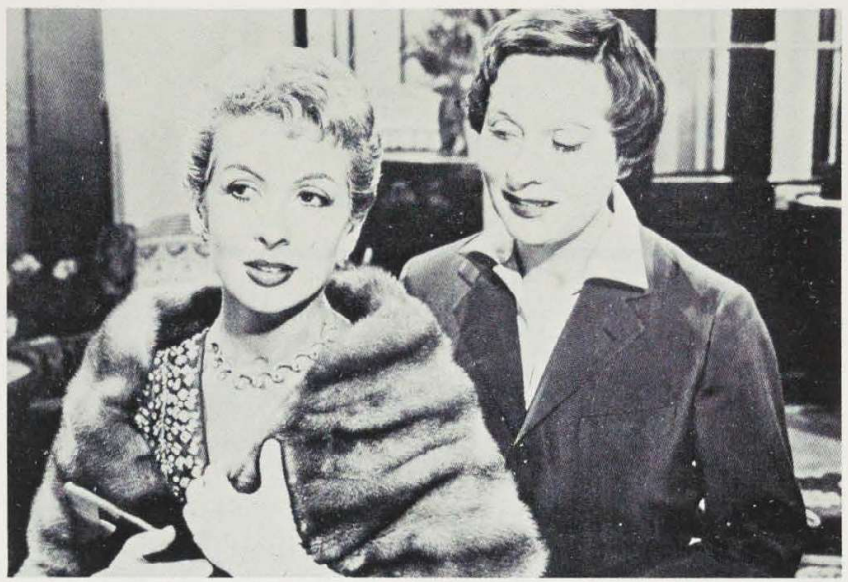

Figure 20 Huis clos (No

Exit), France, 1954.

Production still.

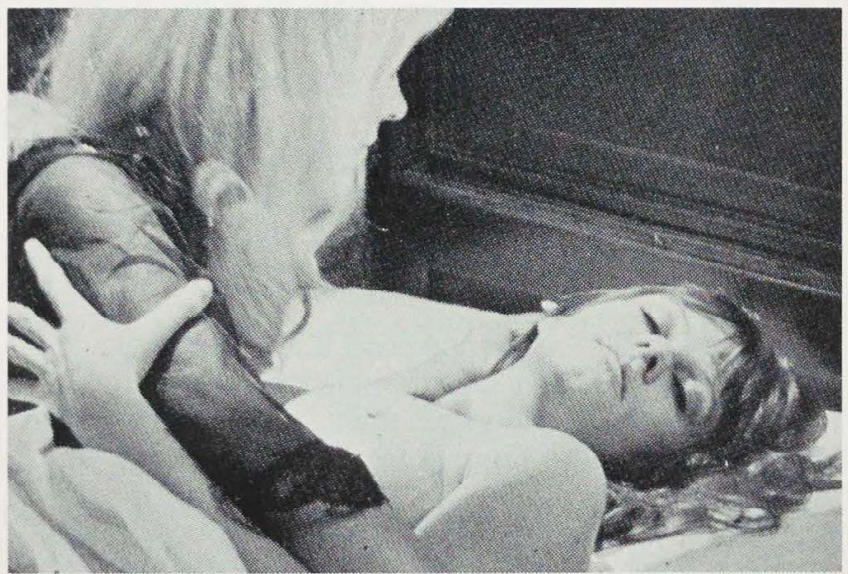

Figure 22 Lust for a

Vampire, Great Britain,

1970. Production still.

or honest seduction but by stealth. This image of malignant lesbian power is explored still further in the use of lesbianism in the vampire film (see Figure 22), where sexual power through stealth, the very heart of the vampire myth, may be articulated with other aspects of fears and taboos concerning women, including the imagery of blood as both sexual juices and menstrual flow. Although undoubtedly intended as negative representations, the very force and vividness of these evocations of female/lesbian power mean that films such as Daughters of Darkness or Blood Beast of Terror might be appropriated as almost radical lesbianfeminist films.

In-betweenism probably remains the most familiar and widespread gay typology. In its tragic and violent modes it reinforces negative views of gay sexuality; in its representation of the nastiness or ridiculousness of not being really one sex or the other, it serves to maintain the notion of rigid gender role differentiation. Yet it may also, through a paradoxical inversion, embody a rejection of those roles. 


\section{Macho}

In The Boys in the Band one of the characters is given a macho-style hustler as a birthday present (see Figure 23) - his exaggeratedly masculine style contrasts with the varieties of queens and sad young men who make up the rest of the cast. By the time of A Different Story, however, the gay man is himself identified by his macho look (see Figure 24). It is an exaggerated masculinity, and indeed its very exaggeratedness marks it off from the conventional masculine look on which it is based. It is, moreover, a consciously erotic look. The practical, instrumental connotations of working-class male clothing are transformed into pure signs of eroticism. The typing of the Perry King character in the still is precise - the stance draws the eye to the crotch; the t-shirt is stretched not only to reveal body contours but to become a tactile surface in its own right; the hair is not just neat but clean as well with the light catching it so that the viewer might wish to run her/his fingers through it.

In marking off the macho man from the simply straight man, this gay type retains the idea of (male) homosexuality implying something different in relation to gender, but here there is no notion of a biological in-betweenism but an excess of masculinity. However whereas in-betweenism is predominantly conceptualized in relation to biological androgyny, macho is far more clearly the conscious deployment of signs of masculinity. In this way macho is close to the other predominant forms of gay male ghetto culture, camp and drag. The latter may be read within the idea of in-betweenism, the queen being, after all, camp in behavior and given to wearing women's clothes. But there is a difference between camp behavior and a camp attitude. The latter implies an ironic stance toward official or mainstream images or representations. Camp in this sense is profoundly denaturalizing Far from expressing a sense of what is natural, it constantly draws attention to the artifices attendant on the construction of images of what is natural. Camp, drag, and macho self-consciously play the signs of gender, and it is in the play and exaggeration that an alternative sexuality is implied - a sexuality, that is, that recognizes itself as in a problematic relationship to the conventional conflation of sexuality and gender

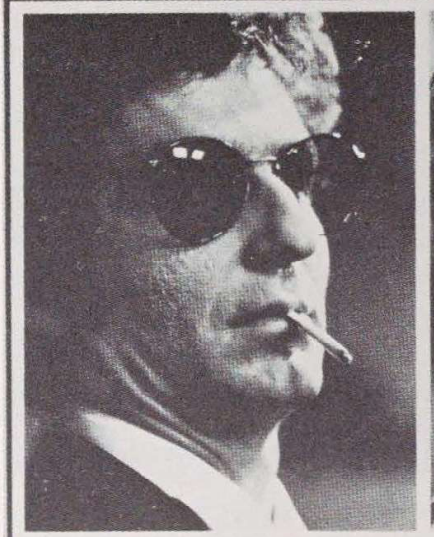

Today is Harold's birthday

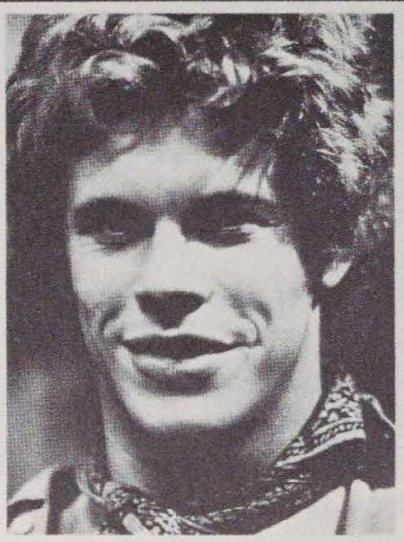

This is his present.

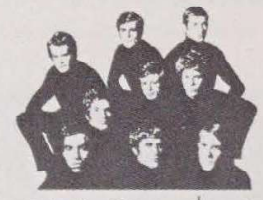

Mart Crowley's

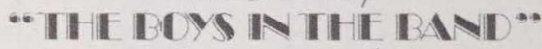

is not a musical.

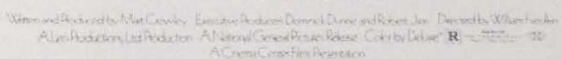

NOW PLAYING - LOEW'S STATE 1 - LOEW'S TOWER EAST

Figure 23 The Boys in the Band, U.S.A., 1970. Press advertisement.

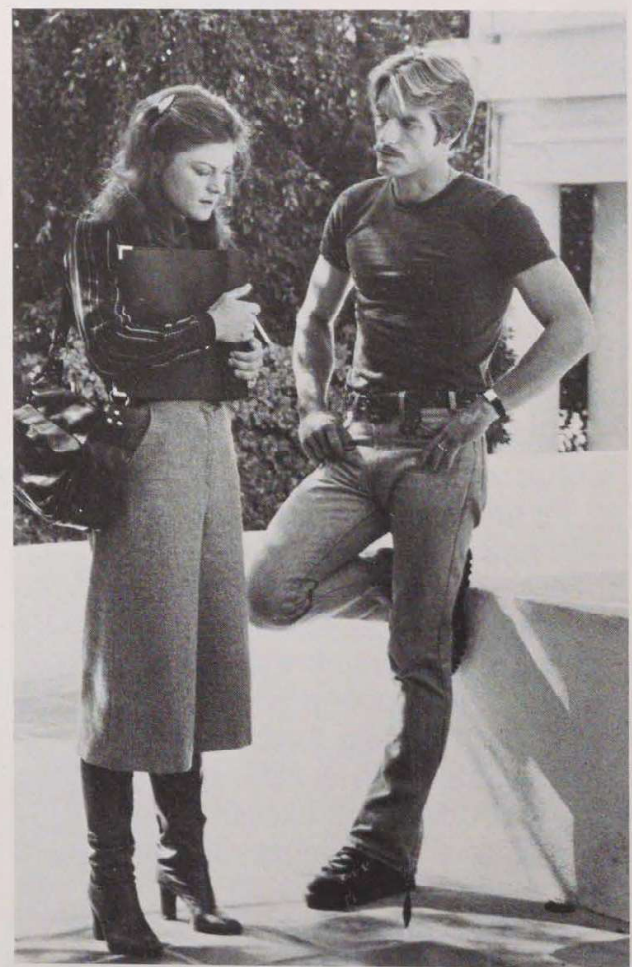

Figure 24 A Different Story, U.S.A., 1978 Production still. (Courtesy of Vito Russo.) 


\section{The Sad Young Man}

In the fifties and sixties it was easy to spot the emergent and still rare gay novel by its cover (see Figure 25). Clean-shaven, young models are lit in ways that both soften their features and also suggest a twilight existence, with all the melancholy associations that twilight has in our culture. Neither man manages directly to catch the other's eye: either one gazes and the other looks thoughtfully (troubledly?) away, or else both look over their shoulders toward but not at each other. Thus everything is young, soft, half-lit, halfestablishing contact, but frozen at that moment, at the moment of yearning. They are "sad young men."

The sad young man is neither androgynously inbetween the genders nor playing with the signs of gender. His relationship to masculinity is more difficult, and thus sad. He is a young man, hence not yet really a real man. He is soft; he has not yet achieved assertive masculine hardness. He is also physically less than a man. In many paperback covers he does not hold his head up but hangs it. There is perhaps an echo in the stance of the major source of this imagery, the Judeo-Christian tradition. The sad young man is a martyr figure.

Christ was a young man on the cross; he is also the most familiar image of a man in Western culture. The crucifix sets the characteristic Christian register of aesthetic response, adoration of a man in pain Subsequent martyr figures, especially St. Sebastian, have developed this register and have also been the occasion for the representation of male beauty. Once again conflating subject and object of homosexual desire, the sad young man embodies a mode of sexuality we might now label masochistic. Not simply despite but because of the history of Christian persecution of gays, the Christian tradition yields an iconography of punishment as pleasure, suffering as beauty, that has been particularly fruitful in the development of gay images.

It is explored in the film Fireworks. The central motif of the film is a photograph of a sailor holding a young man in his arms in a stance that is a visual rhyme with the Christian Pietà (see Figure 26). This photograph, often used to evoke the film and the filmic world of its director, Kenneth Anger, is in itself an image of masochistic homosexual desire. In the film it is looked at by the young man and thus represents his memory or fantasy. (The fact that it is a photograph does not mean in the logic of this film that it represents an event that has actually taken place.) Thus an image of gay desire is also an image of what the gay person is. The face of the young man, in its soft, trou- bled expression, is an icon of beautiful melancholy found equally, for instance, in the book covers, in an even earlier avant-garde film, Lot in Sodom (see Figure 27), and in such gay identification figures as Montgomery Clift and Dirk Bogarde (Figures 28 and 29).

(There are of course other sources of sad young men imagery, notably the image of the romantic hero who, in being the object of [female] desire, thus becomes unmanly and available for gay representation; and the psychoanalytic construction of male fears as expressed through imagery of mutilation and castration, the sad young man in this discourse being the exemplar of the castrated, less-than-mature man.)

\section{Lesbianfeminism}

The film Word Is Out registers a difference between contemporary lesbian and gay male life-styles.

Though concerned to present a range of gay people, and in some ways setting itself against the notion of typicality, the film nonetheless marks a broad distinction between a gay male culture that tends toward artifice and a lesbian culture that tends toward naturalness. The film's musical interludes show this most clearly, not only in the kind of music but in the visual presentation of it. The gay male music is disco, clearly related to Tamla in the accompanying visual production, the line-up of singers following a set routine dressed in identical, showbizzy, sexy clothes. The lesbian music is folk-related, with all that that connotes of ideas of natural music; the singers each accompany themselves on a guitar, a simple, widely available instrument, and do not appear to perform to an audience, as the male group does, but as it were for themselves. Nor are the signs of self-presentation marked as with the men-no makeup, nonshowbiz clothes, indeed checked shirts and jeans that themselves carry rural, naturalistic connotations.

This tendency of lesbian cultural production can be seen elsewhere. The book Eye to Eye: Portraits of Lesbians by JEB is particularly interesting here. Did one not have the title of the book, one would not necessarily interpret photographs like these as lesbian. Yet one does have the title, it is part of the meaning of the photos, and the title renders the lesbianism of the photos visible. The majority of the photos deploy a rhetoric of the natural, in their largely direct (apparently transparent), eye-level approach and in their iconography of, for instance, ethnic or subhippie dress (Figure 30 ), practical, hands-on-tools crafts (Figure 31), even where the technology itself is quite highly developed (Figure 32), and in their use of nature itself (Figure 33). 


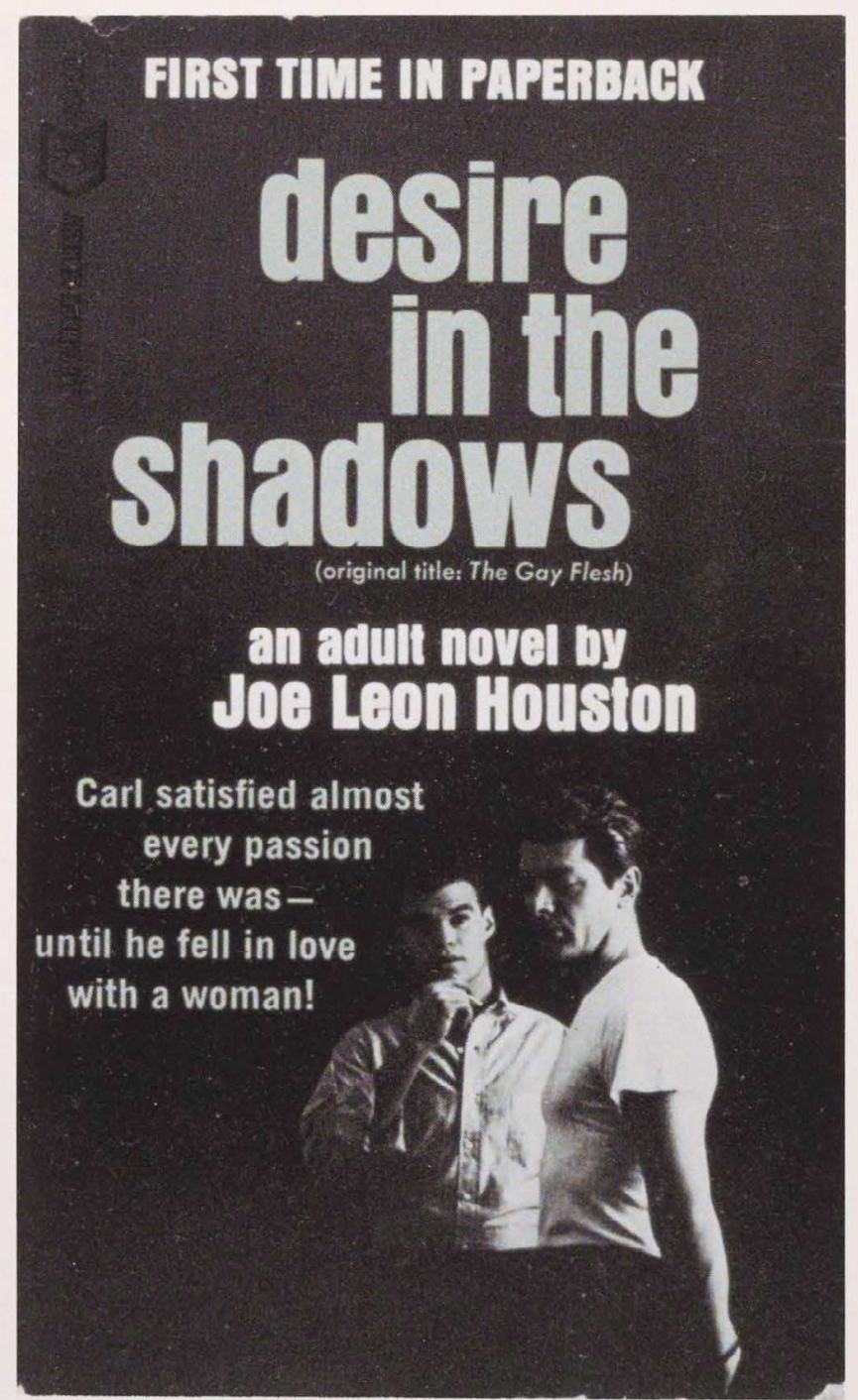

Figure 25 Desire in the Shadows, 1966.

Paperback book cover.

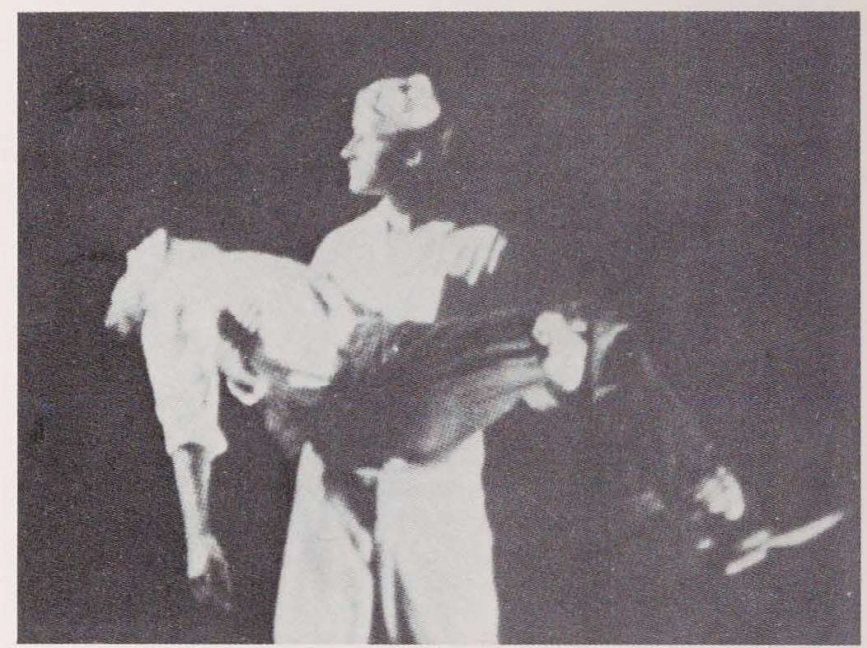

Figure 26 Fireworks,

U.S.A., 1947. Frame enlargement.

This series of photographs, or, for example, the films of Barbara Hammer with their extensive use of flower imagery, is neither an assertion of in-betweenism nor a play on the signs of the natural. A further example from JEB (Figure 34) with its caption illustrates most clearly what is involved. It is a representation of lesbianism as a femininity that is almost pantheistic in origin. It refuses the analytical, taxonomic appropriation of nature that the institution of biology has promulgated, and in this sense it is close to the kind of romantic receptivity to nature of the hippie movement, to which JEB's and Hammer's work is visually quite close. This is, however, crossed with radical feminist ideas that see women as having a special and even mystical relationship to nature, through the traditions of herbal healing and witchcraft, through women's more intimate relationship with the reproduction of human life, through the magical correlation of the menstrual cycle with the phases of the moon, and so on. Lesbianism here is not an object choice but the means to achieve full recognition of this repressed or despised femininity without the repressive, destructive presence of masculinity and male sexuality. Such lesbian imagery is just as involved, on the one hand, with typification in its depiction of a range of variations on a clearly recognizable type, and on the other with a conventional view of nature. To say so, however, is to speak from within the very denaturalizing, rationalistic perspective that such imagery, with good reason, opposes. 


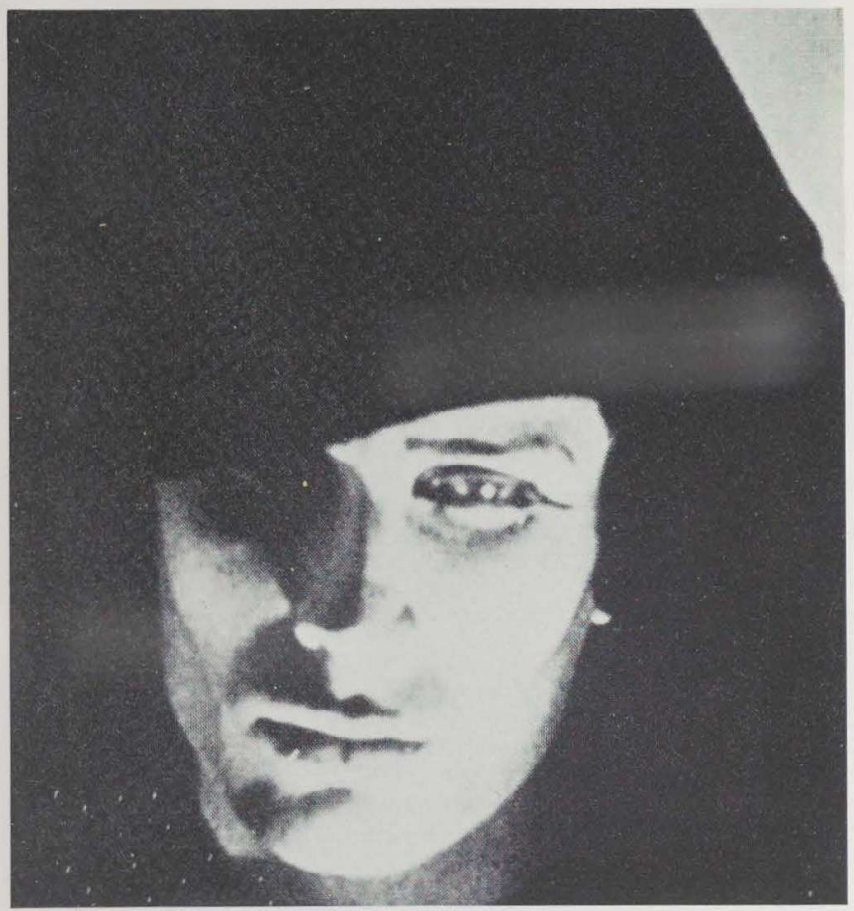

Figure 27 Lot in Sodom,

U.S.A., 1934. Frame

enlargement.

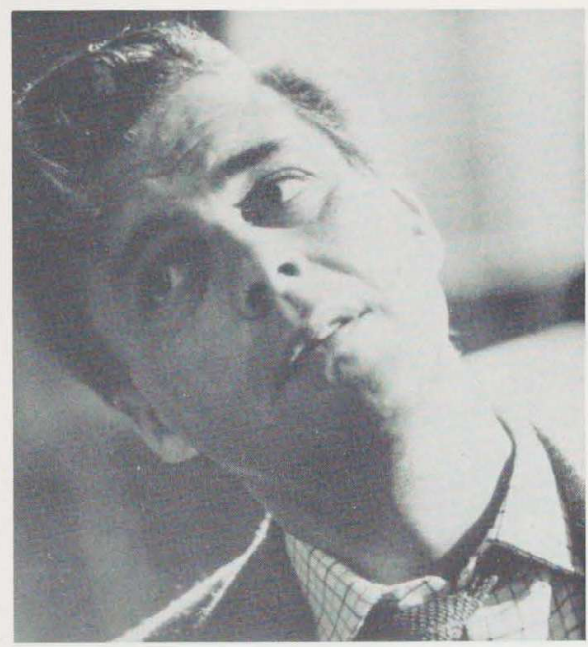

Figure 29 Dirk Bogarde.

Publicity shot for Victim, 1961.
Figure 28 Montgomery Clift. Publicity photo.

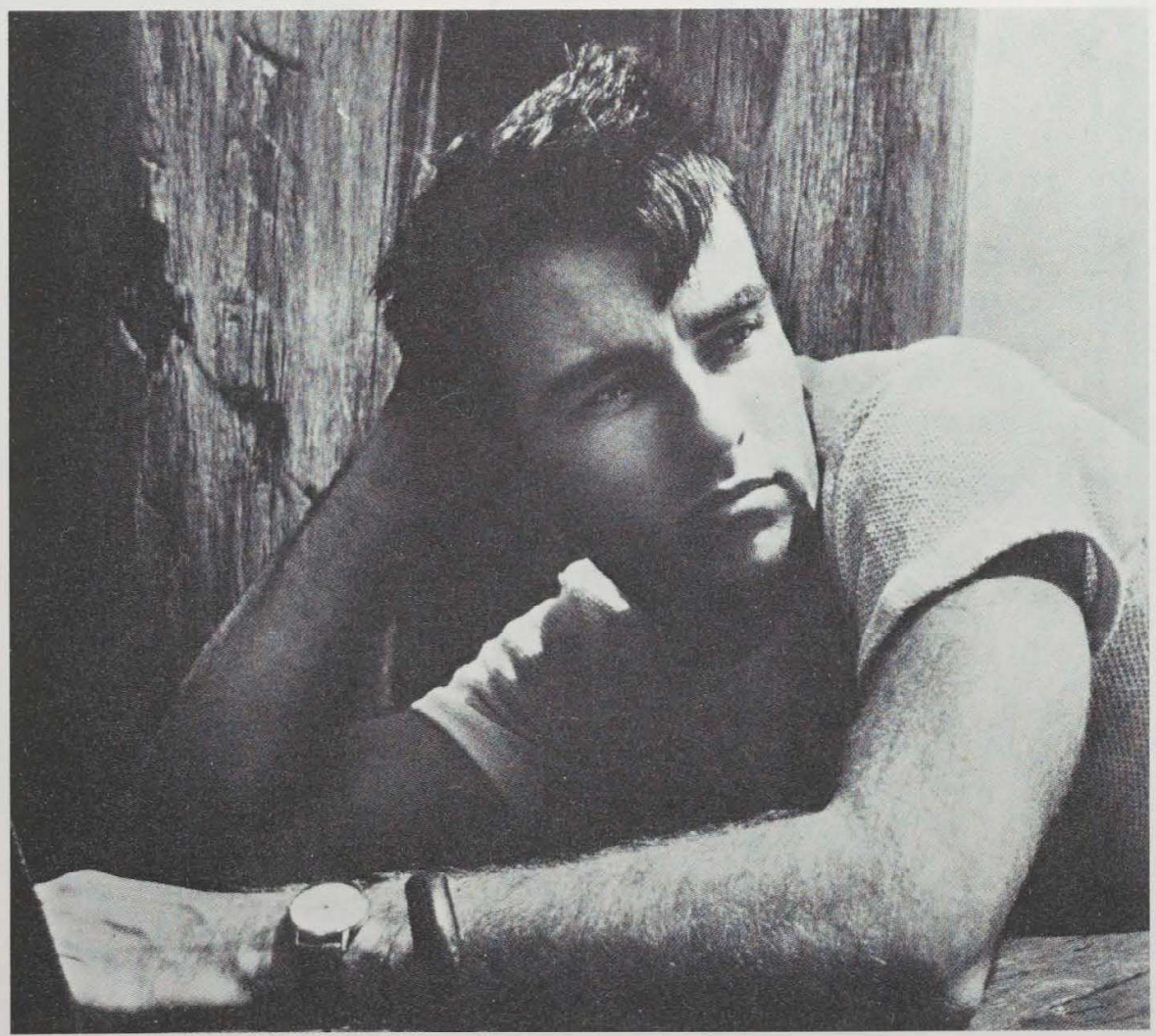




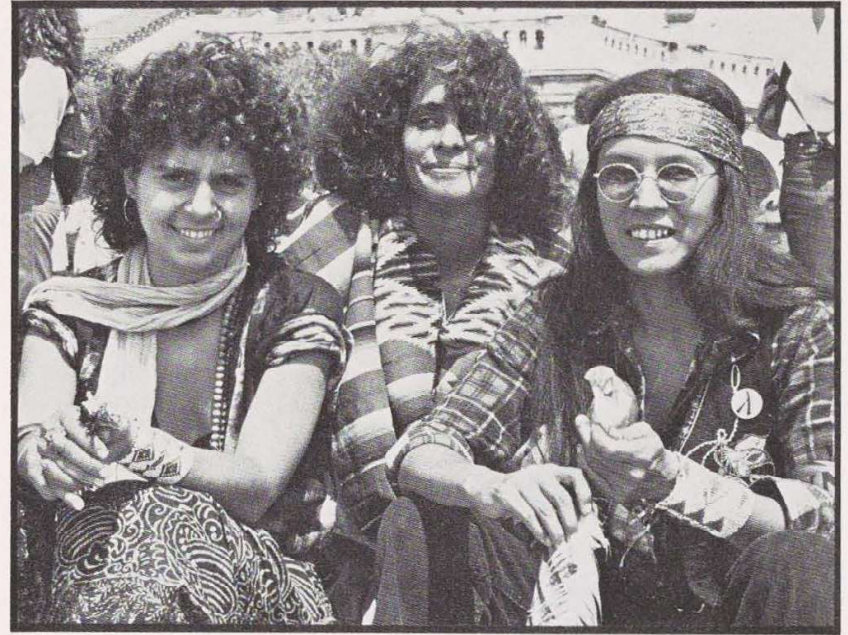

Figure 30 JEB. "Makara, Marta and Burning Cloud. Washington, D.C. 1979." From Eye to Eye: Portraits of Lesbians, Washington, D.C., 1979.

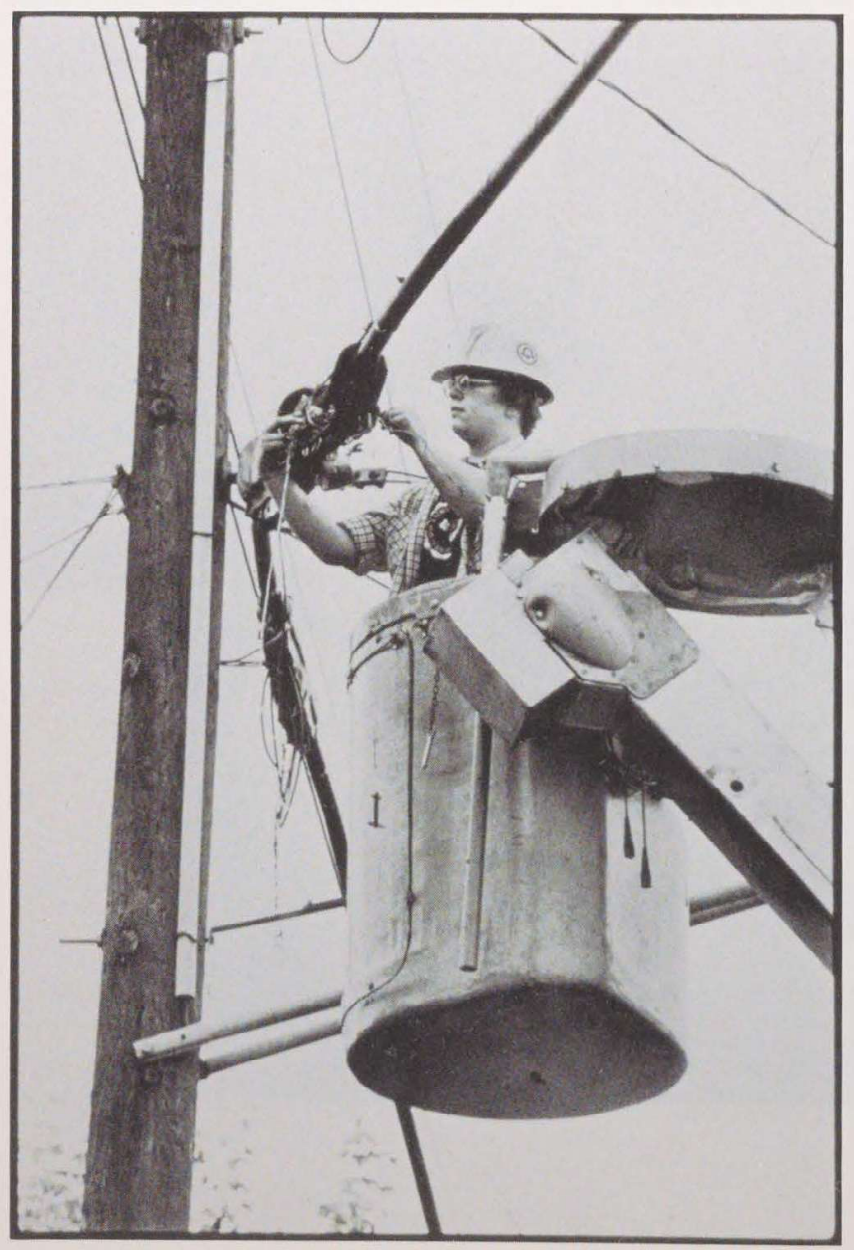

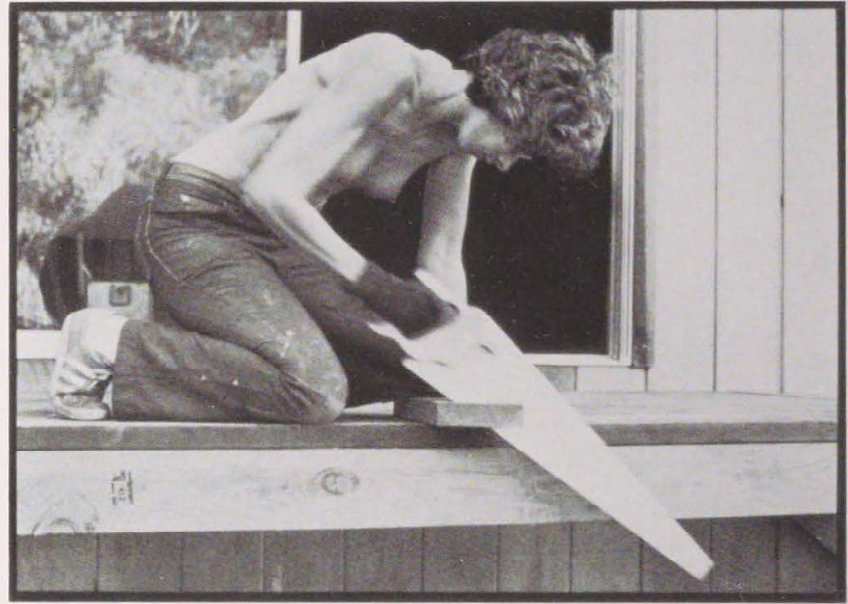

Figure 31 JEB. "Jane. Willits, California. 1977." From Eye to Eye: Portraits of Lesbians, Washington, D.C., 1979.

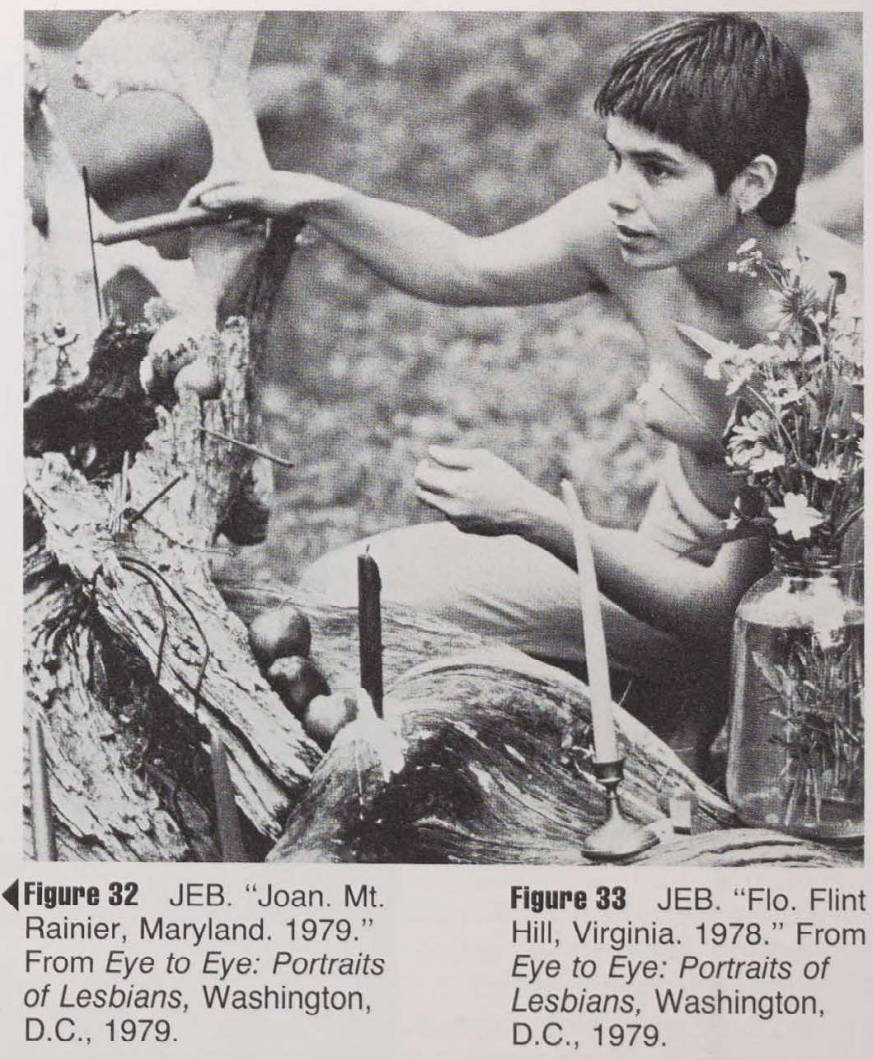




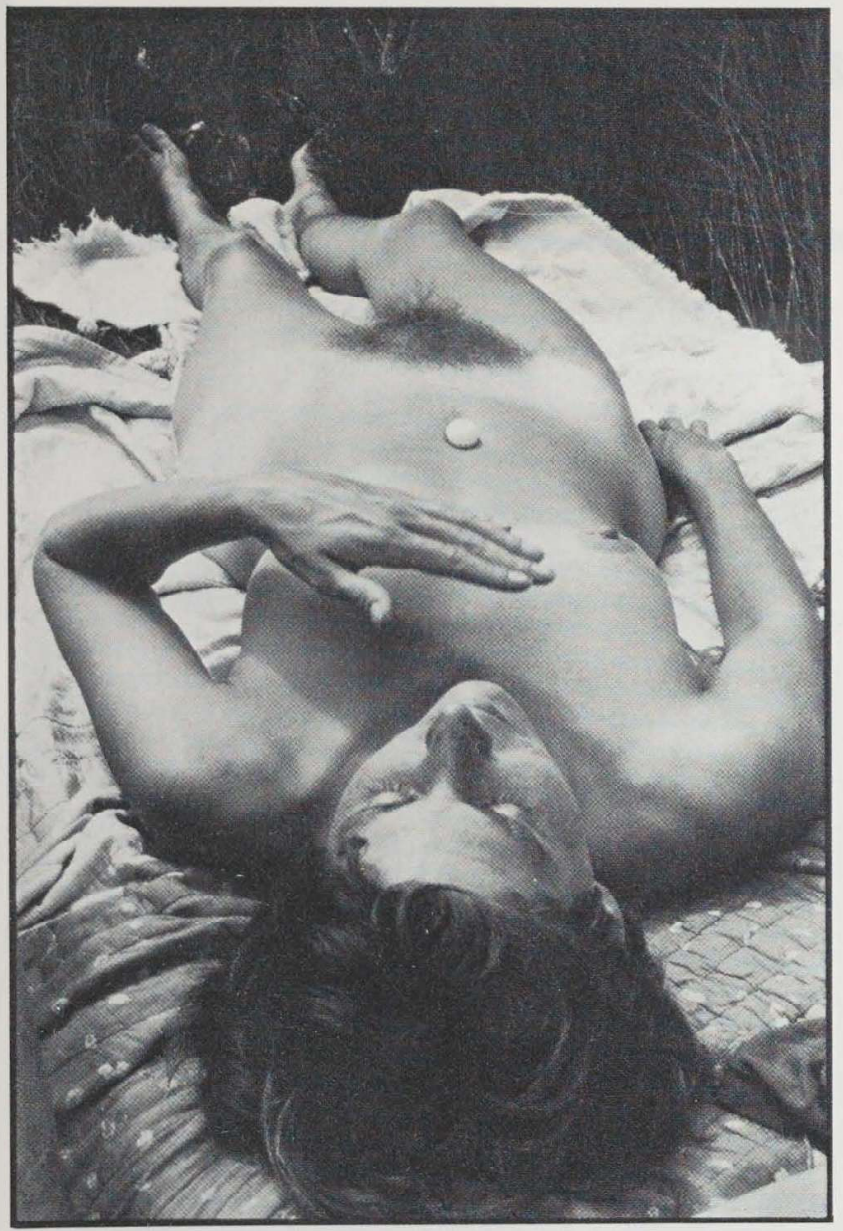

Figure 34 JEB. "Mara. Broomes Island, Maryland. 1976." From Eye to Eye: Portraits of Lesbians, Washington, D.C., 1979. "Under the domination of the egg, one usually finds a prevalence of peaceful, uterine life, satiated, comfortable, complacent, though determined in its defense against outsiders. A matriarchal realm hardly knows such a thing as a war of conquest, although the defense of the domestic egg is stalwart and brave" (Helen Diner, Mothers and Amazons: The First Feminine History of Culture, Julian Press, New York, 1965).

\section{Summary}

My purpose in this article has been to explore some of the complexity behind the apparently simple face of gay types. This very complexity gives them their force, for good or ill, as a mode of representation. The complexity springs in part from the nature of typification, which always condenses a wealth of social knowledge into a few striking and vivid signs. It springs in turn from the types' connectedness to other enormously complex sign systems, for example, competing conceptions of nature and mythologies such as Christianity or the vampire tale. Above all, it springs from the creativity of gay people in producing such rich and varied cultural systems, endowing such simple images with a range of contradictory meanings.

\section{References}

- Fischer, Hal

1978 Gay Semiotics: A Photographic Study of Visual Coding among Homosexual Men. Berkeley, Calif.: NFS Press.

- Gagnon, John, and William Simon

1973 Sexual Conduct: The Sources of Human Sexuality. Chicago Aldine.

- Perkins, T. E

1979 Rethinking Stereotypes. In Ideology and Cultural Production. M. Barrett, P. Corrigan, et al., eds. Pp. 135-159. London: Croom Helm 